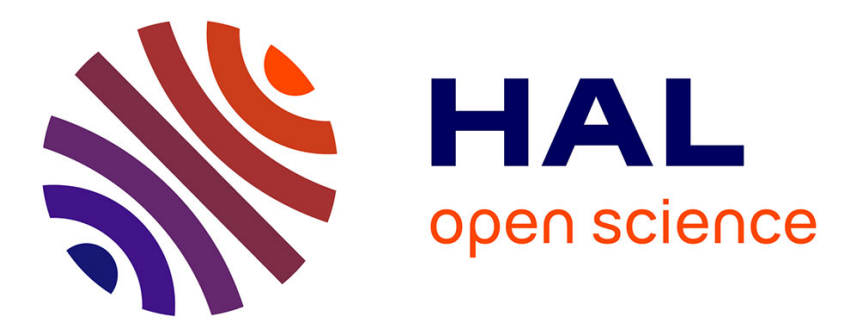

\title{
Stratigraphy in the Mawrth Vallis region through OMEGA, HRSC color imagery and DTM
}

\author{
D. Loizeau, N. Mangold, F. Poulet, V. Ansan, E. Hauber, J.-P. Bibring, B. \\ Gondet, Y. Langevin, P. Masson, G. Neukum
}

\section{- To cite this version:}

D. Loizeau, N. Mangold, F. Poulet, V. Ansan, E. Hauber, et al.. Stratigraphy in the Mawrth Vallis region through OMEGA, HRSC color imagery and DTM. Icarus, 2010, 205 (2), pp.396. 10.1016/j.icarus.2009.04.018 . hal-00612400

\section{HAL Id: hal-00612400 https://hal.science/hal-00612400}

Submitted on 29 Jul 2011

HAL is a multi-disciplinary open access archive for the deposit and dissemination of scientific research documents, whether they are published or not. The documents may come from teaching and research institutions in France or abroad, or from public or private research centers.
L'archive ouverte pluridisciplinaire HAL, est destinée au dépôt et à la diffusion de documents scientifiques de niveau recherche, publiés ou non, émanant des établissements d'enseignement et de recherche français ou étrangers, des laboratoires publics ou privés. 


\section{Accepted Manuscript}

Stratigraphy in the Mawrth Vallis region through OMEGA, HRSC color imagery and DTM

D. Loizeau, N. Mangold, F. Poulet, V. Ansan, E. Hauber, J.-P. Bibring, B. Gondet, Y. Langevin, P. Masson, G. Neukum

PII:

S0019-1035(09)00185-7

DOI:

10.1016/j.icarus.2009.04.018

Reference:

YICAR 9015

To appear in:

Icarus

Received Date: $\quad 19$ August 2008

Revised Date: $\quad 10$ April 2009

Accepted Date: $\quad 14$ April 2009

Please cite this article as: Loizeau, D., Mangold, N., Poulet, F., Ansan, V., Hauber, E., Bibring, J.-P., Gondet, B., Langevin, Y., Masson, P., Neukum, G., Stratigraphy in the Mawrth Vallis region through OMEGA, HRSC color imagery and DTM, Icarus (2009), doi: 10.1016/j.icarus.2009.04.018

This is a PDF file of an unedited manuscript that has been accepted for publication. As a service to our customers we are providing this early version of the manuscript. The manuscript will undergo copyediting, typesetting, and review of the resulting proof before it is published in its final form. Please note that during the production process errors may be discovered which could affect the content, and all legal disclaimers that apply to the journal pertain. 


\section{Stratigraphy in the Mawrth Vallis region through OMEGA, HRSC} color imagery and DTM

Loizeau, Mangold, Poulet, Ansan, Hauber, Bibring, Gondet, Langevin, Masson, 4 Neukum

5

6

7

\section{ABSTRACT:}

The Mawrth Vallis region contains an extensive (at least $300 \mathrm{~km} \mathrm{x} 400 \mathrm{~km}$ ) and thick $(\geq 300 \mathrm{~m}$ ), finely layered (at meter scale), clay-rich unit detected by OMEGA. We use OMEGA, HRSC DTMs derived from stereoscopic imagery, HRSC color imagery and high resolution imagery such as MOC, CTX and HiRISE to characterize the geometry and the composition of the clay-rich unit at the regional scale. Our results show that the clay-bearing unit can be divided into sub-units on the basis of differences in color and composition. In false-colors visible imagery, alternating white/bluish and orange/red colored units correspond to a compositional succession of respectively $\mathrm{Al}$ - and $\mathrm{Fe}$ - or Mg-phyllosilicate rich material. Geological cross-sections are presented along the principal outcrops of the region in order to define the stratigraphy of these sub-units. This method shows that the dips of the sub-units are frequently close to the slopes of the present topography, except for scarps visible at the dichotomy boundary, inside impact craters walls, and outcrops inside Mawrth Vallis. In addition to the Al- and Fe- or Mg-phyllosilicate rich sub-units, an altered surface is identified as the lower basement unit. We propose two possible end-member scenarios to explain the derived stratigraphy: 1. alteration of volcaniclastic, aeolian or aqueous layered deposits of various compositions by groundwater, resulting in distinct altered rocks; or 2. Alteration coeval with the deposition of sediments under varying chemical conditions, in wet pedodiagenetic environment. 


\section{INTRODUCTION}

OMEGA (Observatoire pour la Minéralogie, l'Eau, les Glaces et l'Activité, onboard Mars Express [Bibring et al., 2004]) discovered large outcrops of a phyllosilicate-rich unit, within the exhumed crust in the Mawrth Vallis region [Poulet et al., 2005; Loizeau et al., 2007]. This unit exhibits layers at a meter-scale exposed in outcrops of the light-toned terrains throughout the region (we chose to refer to these terrains as the light-toned terrains, with reflectance at $\sim 1 \mu \mathrm{m}>0.2$, in contrast to the rest of the plateau covered by darker material, with reflectance at $\sim 1 \mu \mathrm{m}<0.15$ ) [Loizeau et al., 2007; Michalski and Noe Dobrea, 2007]. Phyllosilicates are observed within the most exposures of this unit: in figure 1, they are located on the light-toned terrains.

OMEGA distinguished two different types of phyllosilicates with light-toned layered outcrops on the basis of detected absorptions bands at $1.40 \mu \mathrm{m}, 1.93 \mu \mathrm{m}$, and at either 2.20 or near $2.3 \mu \mathrm{m}$. The $1.93 \mu \mathrm{m}$ band is due to the combination of $\mathrm{H}-\mathrm{O}-\mathrm{H}$ bending and stretching overtones, and the band at $1.41 \mu \mathrm{m}$ is due to the combination of $\mathrm{H}-\mathrm{O}-\mathrm{H}$ stretching overtones; there is also a band near $1.4 \mu \mathrm{m}$ due to an overtone of the $\mathrm{OH}$ stretching mode [Clark et al., 1990; Bishop et al., 1994; Bishop et al., 2002]. In addition, the $2.20 \mu \mathrm{m}$ absorption band is found in Al-rich phyllosilicates, due to a combination of $\mathrm{OH}$ stretch and $\mathrm{Al}-\mathrm{OH}$ bend absorptions, a $2.29 \mu \mathrm{m}$ band in $\mathrm{Fe}^{3+}$-rich phyllosilicates (combination of $\mathrm{OH}$ stretch and $\mathrm{Fe}$ $\mathrm{OH}$ bend absorptions) and a $2.32 \mu \mathrm{m}$ absorption band in $\mathrm{Mg}$-rich phyllosilicates (combination of $\mathrm{OH}$ stretch and $\mathrm{Mg}-\mathrm{OH}$ bend absorptions) [Clark et al, 1990; Poulet et al., 2005; Bishop et al., 2008]. Those OMEGA spectra correspond favorably to library spectra of montmorillonite and nontronite [Loizeau et al., 2007], but variations in spectral shapes could indicate the presence of other Al-bearing smectites and Fe-bearing or $\mathrm{Mg}$-bearing smectites and phyllosilicates as well. The OMEGA spectra of the surface of the phyllosilicate-rich outcrops have been modeled by Poulet et al. [2008] to derive their composition. From the perspective of OMEGA, the Mawrth Vallis region presents the highest abundance in phyllosilicates on Mars, with up to $65 \%( \pm 10 \%)$ of smectites in volume. In this study, we chose to refer to the phyllosilicate-rich terrains as the "clay-rich unit". Results from the Compact Reconnaissance Imaging Spectrometer for Mars (CRISM, on board Mars Reconnaissance Orbiter) have recently shown a wider variety of hydrated species in the Mawrth Vallis region at higher spatial resolution, including hydrated silica, kaolinite, and a ferrous phase [Bishop et al., 2008].

The dark terrains of figure 1 contain clinopyroxene, either as highly indurated material and coarse grained sand in the plains, Mawrth Vallis mouth and large crater floors, or as fine and poorly indurated material on top of the plateaus, mantling the clay-rich unit [Loizeau et al., 2007].

HRSC (High Resolution Stereo Camera, onboard Mars Express) provides complete coverage of the region at high resolution ( 15 meters) in color and in stereo [Neukum and 
Jaumann, 2004]. Our study utilizes the DTMs and color imagery derived from HRSC datasets in order to further understand the geometry of this clay-rich unit. New datasets such as the HiRISE images (High Resolution Imaging Science Experiment, onboard Mars Reconnaissance Orbiter) provide additional information about local geology.

This paper first presents the different datasets used in the study and second describes the result of correlation of these with the OMEGA-derived mineralogy of the clay-rich unit. A third part focuses on the stratigraphy of the largest clay-rich outcrops of the region derived from the HRSC color imagery and the HRSC DTM along selected cross-sections. This method produces a better understanding of the general geomorphic trends of the clay-rich layered-unit. Finally, the discussion places the stratigraphic results in the context of the history of the region, and the mineralogy of the phyllosilicates in order to postulate formation mechanisms for the clay-rich unit.

\section{Infrared and visible datasets}

\subsection{OMEGA datasets}

OMEGA is a visible and near-infrared (VNIR) hyperspectral imager providing threedimensional data cubes at spatial sampling from a few kilometers to $300 \mathrm{~m}$. For each pixel, the spectral range is 0.35 to $5.1 \mu \mathrm{m}$, using 352 contiguous spectral elements (spectels), or channels, at 7-20 nm spectral resolution. The spectrometer consists of three detectors (from 0.35 to $1 \mu \mathrm{m}$, from 0.9 to $2.7 \mu \mathrm{m}$, and from 2.5 to $5.1 \mu \mathrm{m}$ ) [Bibring et al., 2004]. This study uses the data recorded by the second detector, whose wavelength domain is dominated by solar reflection and enables the identification of numerous minerals [Bibring et al., 2005]. The data processing, the orbits used to derive the mineralogy of the Mawrth Vallis region, and the chosen spectral indices and their threshold are the same as those described in Loizeau et al. [2007].

\section{2. $\quad$ HRSC image processing}

The HRSC camera is a multi-sensor pushbroom instrument, with nine CCD line sensors mounted in parallel to deliver nine superimposed images for each orbit file. Four of these lines (or channels) are assigned to the color imagery: a "blue" detector centered around $450 \mathrm{~nm}$ ( $\sim 100 \mathrm{~nm}$ in width at half spectral response), a "green" detector centered around 550 $\mathrm{nm}(\sim 100 \mathrm{~nm}$ in width at half spectral response), a "red" detector centered around $750 \mathrm{~nm}$ ( $\sim 50 \mathrm{~nm}$ in width at half spectral response), and an "infrared" (or "IR") detector centered around $950 \mathrm{~nm}(\sim 75 \mathrm{~nm}$ in width at half spectral response), in addition to the panchromatic "nadir" channel (centered around $700 \mathrm{~nm}, \sim 200 \mathrm{~nm}$ in width at half spectral response). We refer to these channels' names throughout the paper. The resolution of the images of the color 
channels is usually 2 to 4 times less than the resolution of the images of the nadir channel for the same orbit file [Neukum et al., 2004; Jaumann et al., 2007].

In this study, the color imagery is used as a tool to discriminate different types of terrains. HRSC RGB color images are computed by composing, without calibration, the IR detector or red detector along with the blue and green detectors. The HRSC RGB images composed with the red channel and those composed with the IR channel show the same boundaries between terrains of the same color. For the purposes of this study, we focus on RGB color imagery and ignore the IR channel (see figure 1 for a mosaic of the whole region with HRSC RGB images). The intent of this paper in not to show true color images nor a spectral correlation between OMEGA and HRSC color channels [McCord et al., 2007].

\subsection{HRSC DTM computation}

The HRSC camera records two images for each orbit assigned to stereo imagery and the computation of Digital Terrain Models (DTM). The stereo channels record images $18.9^{\circ}$ backward and forward from the nadir channel [Neukum et al., 2004; Jaumann et al., 2007; Scholten et al., 2005]. Along with the nadir channel, which is usually better sampled than the stereo channels, a triplet of images is delivered for each orbit and usable for stereo imagery.

A mosaic DTM has been computed for the Mawrth Vallis region using three different HRSC orbits (from east to west, orbits H1293_0000, H1326_0000 and H1337_0009). For the western most orbit 1337, the spatial resolution is $16.9 \mathrm{~m} /$ pixel for the nadir image, 38.2 $\mathrm{m} /$ pixel for one stereo image and $34.2 \mathrm{~m} / \mathrm{pixel}$ for the other stereo image, at the center of the image triplet $\left(\sim 19.2^{\circ} \mathrm{N}\right.$ and $\left.338.6^{\circ} \mathrm{E}\right)$. For the central orbit 1326, their center is close to $34.3^{\circ}$ $\mathrm{N}$ and $340.4^{\circ} \mathrm{E}$ with a spatial resolution of $12.8 \mathrm{~m} / \mathrm{pixel}$ and $27.3 \mathrm{~m} / \mathrm{pixel}$ for the nadir and the stereo images respectively. The last image triplet for orbit 1293 is centered at $30.6^{\circ} \mathrm{N}$ and $341.83^{\circ} \mathrm{E}$ and has a spatial resolution of $12.9 \mathrm{~m} / \mathrm{pixel}, 27.0 \mathrm{~m} / \mathrm{pixel}$ and $27.9 \mathrm{~m} / \mathrm{pixel}$ for the nadir and the two stereo images respectively.

The HRSC Digital Terrain Model (DTM) on the Mawrth Vallis region has been generated using the photogrammetric software developed both at the DLR (German Space Agency) and the Technical University of Berlin [Scholten et al., 2005; Albertz et al., 2005; Gwinner et al., 2007]. Each triplet of images is processed independently before mosaicking each DTM. As the region studied is centered at $24.5^{\circ} \mathrm{N}$ of latitude and $19.5^{\circ} \mathrm{W}$, we chose to ortho-rectify each image triplet in sinusoidal projection centered on the $20^{\circ} \mathrm{W}$ meridian. Then, for each image triplet, the image correlation algorithm was run to find the location of homologous points in the nadir and stereo HRSC images, using a matching process at different spatial grid [Scholten et al., 2005]. The third step is the calculation of the spatial location of 3D object points, defined by Cartesian coordinates in a body-fixed Martian reference system [Duxbury et al., 2002; Seidelmann et al., 2002], using forward ray intersection defined by homologous points and available orientation data [Spiegel et al., 
2007]. The location of each 3D object point is defined with its own accuracy in 3 dimensions $(\sigma \mathrm{x}, \sigma \mathrm{y}$ and $\sigma \mathrm{z})$. At this step, all 3D object points whose location is not sufficiently accurate are removed, e.g. $\sigma \mathrm{x}, \sigma \mathrm{y}$ and $\sigma \mathrm{z}$ must be less than $20 \mathrm{~m}$ [Ansan et al., 2008]. The Cartesian coordinates of 3D object points are then changed in geographic latitude, longitude and height projected on the MARS IAU ellipsoid [Duxbury et al., 2002; Seidelmann et al., 2002]. The height is then calculated taking into account the Martian geoid defined as the topographic reference for the Martian heights (i.e. areoid) [Smith, 1999]. Two maps have been generated at the same scale of rectified images using the VICAR image processing system [MIPL, 2005]: one map of the location of 3D object points and one DTM in which the gap areas are filled by height interpolation. Finally, the orbits are mosaicked in order to obtain a regional map of 3D object points (Fig. 2(a)) and a regional altimetric map of the Mawrth Vallis region (Fig. 2b)).

This process resulted in 11,585,397 homologous points (Fig. 2a) found between $27.5^{\circ} \mathrm{S}$ and $21.3^{\circ} \mathrm{S}$ of latitude, whose $3 \mathrm{D}$ coordinates have a relatively good spatial accuracy $(\sigma \mathrm{x}=7.02 \mathrm{~m}, \sigma \mathrm{y}=4.02 \mathrm{~m}$ and $\sigma \mathrm{z}=4.20 \mathrm{~m})$. The statistical error for the height value is $6.0 \mathrm{~m}$. The number of 3D object points being relatively high, we generate a DTM with a spatial grid close to the resolution of the original images $(40 \mathrm{~m} / \mathrm{pixel})$ in sinusoidal projection centered on the $20^{\circ} \mathrm{W}$ meridian. The spatial distribution of $3 \mathrm{D}$ object points is homogeneous. On the surface covered by the DTM, $23.1 \%$ of the area is devoid (Fig. 2a) of 3D object points, located at the mouth of the channel and within limited areas on the northern and southern sides of the Mawrth Vallis region. These areas are those with dark terrains, consisting of smooth mantling, dunes, and plains, where the matching between the stereo images is not optimum (as shown by Ansan et al. [2008]). The light-toned unit containing clays is always rough enough for a good matching as seen on figures $2 \mathrm{c}$ and $2 \mathrm{~d}$, in which the few voids only occur in dark terrains. We avoid using the HRSC DTM in the smooth areas such as dark dunes and mantling.

The mean regional height offset between MOLA and HRSC DTM is relatively low $(<25 \mathrm{~m})$. There are locally slight height offsets $(<100 \mathrm{~m})$ along the two overlapping areas of DTMs of each orbit, because orbits were processed independently. At the regional scale, the HRSC DTM shows the same topography as MOLA with more details, not apparent on the regional figure.

\subsection{Other visible datasets}

Other high resolution visible datasets were used in order to detect more precise details of the morphology of the terrains. The Mawrth Vallis region has been covered extensively by the MOC camera (Mars Orbiter Camera, on board Mars Global Surveyor [Malin et al., 1992; Malin and Edgett, 2001]) at a resolution between 1.5 and $6 \mathrm{~m} /$ pixel. The Mars Context Imager (CTX, aboard the Mars Reconnaissance Orbiter) provides monochromatic large images at $\sim 6$ 
$172 \mathrm{~m} /$ pixel resolution [Malin et al., 2007] and very-high-resolution data are provided by the

173 HiRISE camera (better than $30 \mathrm{~cm} /$ pixel resolution). In addition to greyscale images obtained

174 through a broad filter centered at $694 \mathrm{~nm}$ ("red" channel), the HiRISE camera offers color

175 images with the use of two additional channels, the "blue-green" filter centered at $536 \mathrm{~nm}$ and

176 the "near infrared" filter centered at $874 \mathrm{~nm}$ [McEwen et al., 2007]. The HiRISE color

177 channels are broader than the HRSC color channels and centered at different wavelengths.

178 The color images presented in this paper are obtained by superimposing HRSC RGB

179 images on top of other higher resolution imagery: HRSC nadir images, MOC narrow angle

180 images, CTX images, or HiRISE images. The high resolution black and white imagery

181 contributes to a higher definition of the final images than the HRSC color imagery would

182 have produced alone. However, color imagery, even at lower resolution, adds essential visual

183 information in the Mawrth Vallis region, helping to define and map geologic units. 


\section{Correlation between HRSC color imagery and OMEGA mineralogy}

Figure 3 displays a comparison of the different smectite-rich (Al-bearing and $\mathrm{Fe}$ - or Mg-bearing) outcrops identified by OMEGA with HRSC color imagery. A set of three images is presented in the figure for each of four sites (located by white boxes in Figure 1): it shows HRSC RGB images (first column), and OMEGA maps of the spectral indices of the $1.93 \mu \mathrm{m}$ (second column), and 2.2 and $2.3 \mu \mathrm{m}$ absorption bands (third column) [Loizeau et al., 2007a].

The different areas of figure 3 are computed with the same regional color stretching as Figure 1, whereas the color images of the following figures have different local color stretching in order to enhance the different tones of the local terrains.

Figure 3a shows two distinct large outcrops on the eastern plateau of Mawrth Vallis: in the first column, we notice a bluish one to the north, Al-smectite rich according to OMEGA data with the combination of 1.9 and $2.2 \mu \mathrm{m}$ bands (second and third columns), and a yellow/pink one to the south (first column), corresponding to $\mathrm{Fe}$ - or $\mathrm{Mg}$-smectites as seen from the combination of 1.9 and $2.3 \mu \mathrm{m}$ band (second and third columns). A part of the western side of Mawrth Vallis is displayed figure 3b, with blue outcrops rich in Al-smectites, especially to the northeast, and yellow/red outcrops rich in Fe- or Mg-smectites. Figure $3 \mathrm{c}$ is located in the western part of the region, with white Al-smectite rich terrains to the north and east, and red/brown Fe- or Mg-smectite rich terrains to the south. Figure 3d is located on the floor of Mawrth Vallis, at the bend of the outflow channel, where polygons of hundreds of meters scale are observed [Loizeau et al., 2007]; here again Al-smectite rich terrains are located on white/bluish outcrops, and Fe- or Mg-smectite rich terrains on yellow/red outcrops.

Thus, these examples all show a distinct composition with color variations (Some of those outcrops were already shown in Loizeau et al. [2006, 2007b] and Farrand et al. [2007]).

Regionally, at OMEGA scale, Al-bearing smectite-rich outcrops always appear as white, grey or bluish outcrops on the RGB composite image (in false colors), as opposed to the other outcrops, which appear in different tones ranging between yellow, orange, red, pink, and brown, corresponding to Fe-bearing smectite-rich outcrops.

This correlation between OMEGA and the HRSC colors always occurs on every wellexhumed outcrop of the clay-rich unit. The redder apparent color of Fe-bearing smectites can be explained by the spectra of such minerals in the visible domain. Figure 4 shows the compared spectra of a nontronite $\left(\mathrm{Fe}^{3+}\right.$-bearing smectite), of a montmorillonite (Al-bearing smectite) and of a kaolinite (Al-bearing phyllosilicate) [Clark et al., 1990; Clark et al., 2007]. The nontronite has a strong absorption at short wavelengths due to $\mathrm{Fe}^{3+}$ in comparison to $\mathrm{Al}-$ bearing phyllosilicates like montmorillonite or kaolinite. The three HRSC color channels used to compute the color images are superimposed in figure 4, delimited by the dashed lines. The ratio of the red channel to the green and blue channels is higher for the nontronite than for the montmorillonite or the kaolinite, explaining why the Fe-smectite rich terrains appear redder. 
221 A similar trend is predictable with the HiRISE color imagery (see figures $5 \mathrm{~b}$ and $5 \mathrm{c}$ ). 222 Although Al-smectite rich rocks are expected over bluish terrains from observations such as 223 in Figure 3, RGB color imagery can serve only as a proxy for the clay mineralogy differences 224 between two terrains and; we are not certain of the Al-rich composition of all blue outcrops, 225 and the Fe-rich composition of all red outcrops.

226 Visible data show at HRSC resolution that color units are spatially distinct and have 227 sharp geologic contacts. This trend is also apparent with OMEGA data, which show distinct 228 mineralogical units with clear boundaries in most cases: spectra with the $2.20 \mu \mathrm{m}$ and the 2.30 $229 \mu \mathrm{m}$ absorption bands simultaneously, exist locally, but are not frequent at a sub-kilometer 230 spatial resolution. In this way, it appears that the clay-rich unit is sub-divided into different 231 color sub-units, each of them corresponding to a distinct composition.

232 Bright reddish dust also covers some part of the region, especially in the eastern and 233 southern part [Loizeau et al., 2007]. Dust mantling can be distinguished from the reddish 234 layers color because the dust would cover equally the dark material adjacent to the bright 235 material (as it does in the eastern part of the region), whereas the reddish layers are restricted 236 to well defined outcrops, and because the dusty terrains correspond to locations where the 237 dust cover is relatively high (dust cover index <0.96) compared to where OMEGA detects 238 phyllosilicates, where the dust cover is low (dust cover index $>0.97$ ) [Ruff and Christensen, 239 2002]. 
3. Stratigraphy of the clay-rich unit through HRSC color imagery and topography

\subsection{Relation between layers and colors}

To understand the geometry of the clay-rich unit, we use high resolution imagery and altimetry to interpret the structure and stratigraphy. This requires that layers can be identified over distances long enough to compare the locations where a layer is visible to the DTM of the outcrop. However, the thinness of individual layers $(<1 \mathrm{~m})$ makes them barely detectable on MOC imagery (resolution around $3 \mathrm{~m} / \mathrm{pixel}$ ) or CTX imagery (resolution around 6 $\mathrm{m} /$ pixel), therefore any single layer cannot be definitely identified and followed over kilometer long distances. HiRISE images allow tracking single layers over the whole image, but the coverage of the region is still very limited. A regional study of the stratigraphy is not possible with these datasets, but the clay rich outcrops can be divided into broader color subunits on HRSC imagery. Each of these color sub-units contains many individual layers. Color sub-units are trackable over tens of kilometers on HRSC images and from one HRSC image to another, when the clay-rich outcrops are well exhumed. The study of the HRSC color imagery with the use of HRSC DTMs is a possible way to better understand the geometry of the clay-rich regional unit.

The question of the relation between the different color sub-units and the meter-scale layers is therefore crucial to the understanding of the stratigraphy of the region. Sub-units defined by colors (and composition) might be decorrelated from the thin individual "physical" layers seen on MOC or HiRISE imagery. If the alteration took place after the deposition of the material, and without relation to its layering, then the color sub-units could follow alteration (such as diagenetic horizons) rather than the lithologic units. This means that the geometry of the layers obtained from colors corresponds to that of the alteration, which might not be that of layers deposition.

A direct way to compare the organization of the color sub-units and the individual layers of the clay-rich unit is to look at crater walls. All craters of the region displaying layering on their walls (generally craters with diameter from 2 to $6 \mathrm{~km}$ ) have been imaged at a $12 \mathrm{~m} /$ pixel resolution by HRSC, and at a $54 \mathrm{~m} /$ pixel color imagery resolution. A few of them have been imaged by MOC and HiRISE in grey scale and in color. Figure 5a presents 2 craters on a composite color image, with height contours from the HRSC DTM. Figures $5 b$ and $5 \mathrm{c}$ shows a succession of different groups of layers on the wall of the western crater, distinguished by their different colors. As illustrated by the sketch at the left of the figure 5c, from the floor to the top, a succession of light brown layers constitutes a first sub-unit, dominated by another, thinner succession of blue layers, building up a second sub-unit; a very thin (two to three layers) yellow sub-unit is present in this blue sub-unit. Above lays a thicker 
yellow sub-unit, a blue sub-unit, and a light brown surface. This crater, which can be considered as a natural cross-section of the clay-rich unit, shows that the unit is subdivided into different color sub-units, laid on top of each other. Each of these sub-units (typically 30 to $50 \mathrm{~m}$ apparent thickness in this crater, see figure 5) is composed of many individual layers (>10) visible only on high resolution imagery (MOC, HiRISE). This compositional and color layering has also been observed on other outcrops with the help of CRISM and other HiRISE color images [Wray et al., 2007; McKeown et al., 2007; Bishop et al., 2007; Wray et al., 2008; Bishop et al., 2008].

At much larger sampling, HRSC color imagery shows the same different sub-units with similar color trends (Fig. 5b). Figure 5 also shows that layers visible at the HiRISE scale follow approximately the dip of colors sub-units, thus suggesting that color sub-unit's and individual layer's geometries are similar, at least in some locations. In the case of a total correlation between the color sub-units and the thin layers, the sub-units can be used as a reliable indicator to study the stratigraphy of the layered unit, hence to get a better understanding of the deposition of the material. However, if the color sub-units and the thin layers are not entirely correlated, the study of the geometry of the sub-units would inform about the process of alteration building the sub-units, but not about the deposition of the material.

In the next sections, we apply classic structural geology methods using HRSC color imagery and HRSC DTM (as well as higher resolution grey scale imagery) to make geological cross-sections of several areas of interest following a strict methodology. A topographic cross-section is done first crossing irregular relief (craters, buttes) using the HRSC DTM. Second, the location of each color sub-unit is plotted at the surface of this topographic cross-section using the color composite image. Third, the apparent dip of layers in the direction of the section is locally constrained by the topographic features that help to follow sub-units on the color imagery. In this way, the apparent dips are averaged over

302 distances of several $\mathrm{km}$, with precisions for the values of elevation of each reference point of $\sim 20 \mathrm{~m}$ (taking into account the height precision of the DTM at one point, and the precision of the location of the color edges on the cross-section: this leads to an error of $<0.5^{\circ}$ for the values of the apparent dips, assuming layers are roughly planar. In this method, dips are measured along the cross section, so they can be underestimated if the maximum dip is in another direction. Fourth, we extend the layering observed at the surface into the subsurface given local dip measurements and interpretations related to these layers. This method is applied in different sections throughout the region, in order to determine the geometry of the whole clay-rich unit. 
The morphology of this large outcrop $(50 \mathrm{~km} \times 60 \mathrm{~km})$, presented in Figure 6 of the western part of the region is characterized by a $40 \mathrm{~km}$-long scarp trending from southwest to northeast, that cuts the highlands above Chryse Planitia. This is one of the few scarps where clear layering is observed in the Mawrth Vallis region. Five different sub-units seem to crop out of the scarp, as represented on the cross-section (figure $6 \mathrm{~d}$ ) by the five beds of different colors; their boundaries along the scarp follow approximately the elevation contours, showing that the layering is sub-horizontal in this area. The constrained cross-section in figure $6 \mathrm{~d}$ illustrates the geometry in this scarp, crossing the scarp and a crater $800 \mathrm{~m}$ in diameter, which displays $2 \mathrm{~km}$ wide ejecta of orange color. We interpret that this crater ejected some orange color material from a layer beneath the surface. This gives an indication about the maximal depth of the orange sub-unit at the place of the crater: this sub-unit should be less than about $80 \mathrm{~m}$ in depth if excavated by the crater (one tenth of the diameter [Melosh, 1989]). Knowing the elevation of the same sub-unit on the scarp, it is possible to derive the dip of the orange sub-unit, which should be about half a degree in the direction of the cross-section. This dip remains poorly constrained due to approximations on the depth and thickness of the layer. Nevertheless, observations at the scarp exclude steep dips, or we would see the layers crossing the plateau surface. The uppermost sub-unit that constitutes the highland plateau top dips slightly to the north by a maximum of $1^{\circ}$, in agreement with the dip of the orange layer 330 below.

331

332

333

334

335

336

337

338

339

340

341

342

343

344

345

346

347

348

To the south of this scarp (Figure 7), a domical form $18 \mathrm{~km}$ in diameter stands out of the plateau, up to $470 \mathrm{~m}$ above the surrounding terrains. The flanks ( $5 \%$ slope) of this shallow dome and its top are light-toned, relatively eroded (Fig. 7a), and show weak signatures of hydrated minerals on OMEGA spectral data (Fig. 7b). A circular pit $5 \mathrm{~km}$ in diameter lies on the northern flank of the dome. Its morphology with gentle walls and shallow depth $(<50 \mathrm{~m})$ questions its origin as an impact crater, especially compared to other impact craters in the region, which show steeper slopes of their walls. In addition, it sits almost on the top of the dome and a lobate shape is visible down slope on its northern side (Fig. 7c). This lobate form is down to $70 \mathrm{~m}$ deep, $2.7 \mathrm{~km}$ large at most, and $5 \mathrm{~km}$ long. Its floor looks greenish on the HRSC RGB composite image, a color not frequent in the region. However, those greenish outcrops are small $(<1.5 \mathrm{~km}$ large $)$ and the absorption bands are too weak on OMEGA spectra to determine the nature of the minerals in this feature. This landform is unique in the whole region from the present dataset, and its origin is debated in section 4.1.

Another region of interest is located east of the dome. Four different sub-units are observable, from east to west, following the cross-section line of Figure 8a: (dm) a dark terrain (HRSC albedo around 16\%), corresponding to a probable wind-blown pyroxene- 
bearing dark mantle (as detected by OMEGA) described in Loizeau et al. [2007]; ( $\alpha 1)$ a white/bluish terrain (HRSC albedo around 27\%), corresponding to the terrains rich in Albearing smectites (as seen with OMEGA, figure 3c), slightly higher in thermal inertia than the dark terrain; ( $\alpha 2)$ a reddish terrain (HRSC albedo around 24\%), corresponding to the terrain rich in Fe- or Mg-bearing smectites (as detected with OMEGA, figure 3c), showing the same relative thermal inertia as the white terrain (the white/bluish and the reddish terrains are both heavily eroded, showing very few small craters); (a3) a brown terrain, also $\mathrm{Fe}-$ or $\mathrm{Mg}$ bearing smectites rich (fig. 3c), but showing many craters several hundred-meters in diameter, a darker tone (HRSC albedo around 19\%) and a thermal inertia higher than $\alpha 2$.

As seen on the cross-section of Figure $8 \mathrm{c}$ and the height contour level of the context image, the brown outcrop ( $\alpha 3)$ is higher in elevation. Thus, along the cross-section, the white/bluish and reddish terrains alternate while the elevation decreases towards the east. We interpret the different reddish outcrops to belong to the same reddish sub-unit ( $\alpha 2)$ because the white/bluish sub-unit $(\alpha 1)$ constitutes residual mesas that do not interrupt the terrain but are superimposed over it. Hence, the dip of sub-unit $\alpha 1$ (in the direction of the cross-section) can be retrieved with the elevations of the boundaries between the white/bluish and the reddish terrains. A $\sim 1.4^{\circ}$ dip to the east is obtained for sub-units $\alpha 1$ and $\alpha 2$. This implies that the brown sub-unit ( $\alpha 3)$, in the western part of the cross-section, is actually stratigraphically lower than the other two sub-units $(\alpha 1)$ and $(\alpha 2)$. This sequence is confirmed by the detailed observation of buttes inside the brown unit ( $\alpha 3$ ) (Figure 8b). We observe locally buttes of reddish material, and locally whitish at the summit, lying at the top of the brown unit $(\alpha 3)$. This is consistent with the stratigraphy deduced from the dips and slopes in the whole area. The overall stratigraphy is illustrated by a detailed cross-section (Fig. 8c). The thickness of the brown sub-unit $(\alpha 3)$ is unknown, since we do not see its bottom, but the reddish sub-unit $(\alpha 2)$ seems to be $\sim 60 \mathrm{~m}$ thick. The white/bluish sub-unit $(\alpha 1)$ has been partly eroded and it is not possible to determine its original thickness, however a minimum original thickness is $\sim 40$ $\mathrm{m}$ (corresponding to its present maximum thickness). Finally, the brown unit ( $\alpha 3)$ lies below the reddish sub-unit $(\alpha 2)$, which is below the white/bluish sub-unit $(\alpha 1)$, capped by the dark mantle $(\mathrm{dm})$. The implications of this stratigraphy are presented in section 4.2.

Here and in the following cross-sections of this study, we choose to number the subunits from top to bottom, inversely to the usual geologic numbering, and the chronological order of deposition of the sub-units. Indeed, we do not know a priori how many sub-units are present and which one is the truly lowest in the stratigraphic section, and so "sub-unit 1" was chosen to be the topmost sub-unit.

Figure 9 illustrates the western part of the clay-rich unit, showing a perspective view (3x vertical exaggeration) of the landforms of Figures 6, 7 and 8, looking towards the south, with the scarp in the foreground. A continuity of the sequence of layering in the whole area is difficult to establish due to the lack of stratigraphic information at the dome. 


\subsection{Central highlands}

388

389

390

391

392

393

394

395

396

397

398

399

400

401

402

403

404

405

406

407

408

409

410

411

412

413

414

415

416

417

418

419

420

421

422

423

424

A large part of the clay-rich unit crops out of the plateau directly to the south-west of the Mawrth Vallis mouth. This $60 \mathrm{~km} \mathrm{x} 90 \mathrm{~km}$ area is relatively flat (slopes $<0.5^{\circ}$ ), with its eastern side in the Mawrth Vallis channel, and its northern side bounded by a chaotic terrain with buttes and small canyons (Fig. 10a). The highest part of this area is mantled by a flat dark pyroxene-bearing material, while the rest of the plateau consists of strongly eroded lighttoned outcrops of the clay-rich unit [Loizeau et al., 2007].

Figure 10 shows two close-ups of this unit: in $10 \mathrm{~b}$ a crater $3.8 \mathrm{~km}$ in diameter, displaying a set of, at least, four different color sub-units. The resolution of the HRSC color images and the HRSC DTM makes it difficult to distinguish the exact thickness of those subunits at this location. In figure 10c, a typical outcrop of the clay-rich unit on this plateau area shows many buttes and troughs of different colors, revealing the presence of different subunits, outcropping through the local differences in elevation created by the erosion.

Additionally, two close-ups of a HiRISE image of this central plateau are shown in Figure 11. Most outcrops of the clay-rich unit show networks of cracks defining small polygons on the surface, whatever the sub-unit. In Figure 11a, the blue layers on the floor of the small canyon show many small blocks from $10 \mathrm{~m}$ to less then $50 \mathrm{~cm}$ in size. Small dark dunes (up to $150 \mathrm{~m}$ long, $20 \mathrm{~m}$ wide) cover parts of this canyon floor, smaller similar dunes are also present on the top of the plateau. Figure $11 \mathrm{~b}$ shows a layered butte surrounded by eroded layers. Those layers are fractured into blocks. We see here that fracturing affects different sub-units.

The outcrops of the clay-rich unit in this area reveal the presence of four different subunits, covered by a dark mantle (dm): ( $\beta 1)$ white/bluish terrains, most of them situated directly underneath the dark pyroxene-bearing mantle, corresponding to Al-smectite rich terrains, of maximal thickness less than $100 \mathrm{~m}$. The largest part of the exhumed terrains correspond to some orange to red outcrops of sub-unit ( $\beta 2)$, up to $100 \mathrm{~m}$ in thickness, and are rich in Fe- or Mg-bearing smectites (see Figure 3b). Local outcrops of another white/bluish sub-unit ( $\beta 3$ ) are also visible, for example on the floor of the small canyon figure 11a, its thickness varies from a few tens of meters to zero. Finally, darker, brown outcrops ( $\beta 4)$ also appear in smaller patches in the south-west and north-east of the described area (also visible on the down-left of Figure 10c), also corresponding to Fe- or Mg-smectite rich terrains. Those brown outcrops are located in troughs, corresponding to the deepest stratigraphic unit visible in the area.

A $75 \mathrm{~km}$-long cross-section (figure 10d) is created in a north-south direction on the plateau, displaying the four observed color sub-units: a light blue one ( $\beta 1$ ) (for the white/bluish terrains), located directly underneath the dark mantle $(\mathrm{dm})$; an orange one ( $\beta 2)$, which corresponds to the yellow, orange and red terrains on the HRSC color imagery; another light blue sub-unit ( $\beta 3$ ) of varying thickness, which disappears locally, and an underlying 
brown sub-unit $(\beta 4)$, whose lower contact is not visible. Any potential underlying sub-unit cannot be seen with the present data sets. The sub-units are close to horizontal on the plateau, and dip gently $\left(<1.5^{\circ}\right.$ dip) towards the north and the Mawrth Vallis mouth. Here, the layers' dip is very close to the slope of the plateau to the north.

\subsection{Exposures in the flanks of Mawrth Vallis and plateau}

\subsubsection{Topography and fluvial morphology of Mawrth Vallis}

Before looking at the bedrock composition, a quick look to the fluvial landforms might help the general view of that part of the region. Figure 12 shows a set of three topographic cross-sections of the Mawrth Vallis channel, using the same scale for an easy comparison. Red and blue dashed lines indicate possible levels of the flow based on the presence of terraces. Terraces are not visible on the full length of both sides of Mawrth Vallis, due to crater impacts, erosion or wind-blown material, which have erased part of them, for example in the erosional window seen on the eastern side, in the bend, figure $14 \mathrm{c}$. The most obvious terraces are located in the upper part of Mawrth Vallis (section 3 in Figure 12). In section 3, the steep slope below this terrace is interpreted as being due to the incision by the outflow, whereas the upper part of the valley displays more gentle slopes. This terrace indicates a level of 400 to $500 \mathrm{~m}$ depth (red dashed line) above the present floor. It is difficult to follow it downstream, but local terraces are visible at about same flow level (as seen with the red line in profiles 1 and 2). In addition, ejecta from a large impact craters on the eastern side of the valley could have buried ancient terraces in profile 2 .

A flow level nearly $800 \mathrm{~m}$ above the present channel floor elevation would be required to explain the whole valley formation, as indicated by the blue line in Figure 12. The blue line in the first profile would imply that there was flow over the plateau near the mouth of Mawrth Vallis (Fig. 10), where the plateau is particularly eroded (Fig. 10c and 11). Such level is possible but it requires a deep flow and it lacks evident terraces higher than those shown by the red level. Thus, the red level might be more realistic, based on clear terraces and does not require an overflow in the downstream section. The red level would require a valley to be already present before the incision of Mawrth Vallis, and in fact, the overall topography of the region shows heights and troughs unrelated to the outflow channel and which could be due to older events. Hence Mawrth Vallis flow was partly controlled by the preexisting topography in which valleys existed.

The floor of Mawrth Vallis displays few landforms possibly related to its erosion. About ten-kilometer-long lineations are observed on the Mawrth Vallis floor. They appear as straight or gently curved dark lines that turn around the streamlined islands (see the white arrows, Fig. 12c). These lineations might correspond to grooves created by the flow into the floor of the channel indicating in that case an erosion of the light toned unit by the flow. 
High resolution images of light-toned, layered rocks on the valley floor are visible near a streamlined island (Figure 12c). Two HiRISE close-ups (Figure 12d and 12e) are located close to the floor of Mawrth Vallis, on the sides of the same streamlined island, with many light-toned layers visible. These layers are steeply dipping as evidenced by their straight traces when outcropping at the surface, even when they cross buttes: the direction of the lines delimiting the layers would change when approaching the buttes if they were horizontal. Another important observation from these two examples is that a group of layers has its color changing laterally along the same section of layers, in contrast to most HiRISE observations in the region.

\subsection{2. $\quad$ Lower Mawrth Vallis section and surrounding plateaus}

One of the places with the deepest $1.93 \mu \mathrm{m}$ band is located in the central part of the region, on a very well exhumed terrain close to the west flank of the Mawrth Vallis channel. Figure 13 presents a cross-section created along a line crossing this well exhumed terrain. This plateau shows two clear color sub-units, grey at the top $(\gamma 1)$ and orange underneath $(\gamma 2)$, locally covered by a dark mantle $(\mathrm{dm})$. Two other sub-units were identified in the Mawrth Vallis side, a thin white/bluish one $(\gamma 3)$, and a brown one $(\gamma 4)$, but these are more difficult to observe at the HRSC resolution. A problem faced in determining the stratigraphy of the clayrich unit here is that the side of the valley is strongly covered by dark material. The proposed cross section is one possible geometry.

An alternative geometry can be proposed by observing the blue patches inside the valley side below the dark mantle. It seems to correspond to a single layer, covering layers of different tones, even if this is difficult to prove since the blue patches are not continuous. They seem to cover directly sub-units $\gamma 2, \gamma 3$ and $\gamma 4$ in Figure 13c, and apparently a variety of colors below the point $\mathrm{C} 2$ in the valley side, although the lack of better resolution does not show clearly the stratigraphy here. This geometry could suggest a color "unconformity" between the blue patches and the layers below, $\gamma 1$ possibly continuing downslope. No obvious layering is visible on the channel side below layers $\gamma 4$, but local layered outcrops are present close to the floor of Mawrth Vallis (see Figure 12d and 12e on the streamlined island sides).

3.4.3.

\section{Upper Mawrth Vallis section and surrounding plateaus}

Figure 14 represents the western side of the upper section (Figure 16). It displays a terrace (indicated in Figure 14a), corresponding to that of the $3^{\text {rd }}$ topographic cross-section in Figure $12 \mathrm{~b}$. This terrace is covered by dark mantle material except in a few areas shown by figure $14 \mathrm{c}$ and $14 \mathrm{~d}$ where the dark mantle and the terrace have been eroded. Both exhumed outcrops display a layering of light-toned material. Figure 14c shows an outcrop that appears to be clay-rich as seen on the right side in Figure 3d. Close-up $14 \mathrm{c}$ is close to the deepest depression on the Mawrth Vallis floor (the elevation is from $-3200 \mathrm{~m}$ to $-3350 \mathrm{~m}$ in this 
image), and is composed of two light-toned layered sub-units (white-blue at the top, and orange/pink below). Figure $14 \mathrm{~d}$ shows also that layering, at a much higher resolution, is present at the base of the side of the channel. Dips are difficult to measure at this location but they appear to be close to horizontal or slightly to the west.

A few other local cross-sections were made at different places on the sides of Mawrth Vallis. Figure 15 shows two local cross-sections, on opposite sides. The first (Fig. 15a and $15 \mathrm{~b}$ ), on the right bank of Mawrth Vallis, was made next to a crater where the clay-rich unit is well exhumed, and several color sub-units can be observed. Three sub-units were found along the cross-section: a grey-bluish at the top, a thinner orange one, and a white one underneath. Given the topography and the sub-units' outcrops, the layers here have gentle dips: we measured a dip $\sim 2^{\circ}$, close to the slope of about $3^{\circ}$. Light-toned sub-units are also visible at the foot of the valley, with a light blue sub-unit on top of an orange one.

A cross-section was constructed on the left bank, north of the first one (Fig. 15c and 15d). This place has also been covered by CRISM and HiRISE data [Wray et al., 2007]. It shows a layering of three different sub-units: a white Al-smectite rich sub-unit between an orange $\mathrm{Fe}$ - or $\mathrm{Mg}$-smectite rich sub-unit at the top, and a light brown $\mathrm{Fe}$ - or $\mathrm{Mg}$-smectite rich sub-unit underneath. A dark brown surface, clay-rich, similar in albedo to $(\alpha 3)$ of figure 8 , may also be present underneath the light brown sub-unit, at an elevation between -2800 and $2850 \mathrm{~m}$. The dip measured for the sub-units of this outcrop shows a broad syncline towards Mawrth Vallis channel, with a maximum dip of $3.3^{\circ} \pm 0.5^{\circ}$.

For this southern region of Mawrth Vallis, these local cross-sections helped to correlate the color sub-units visible on each side of the large channel. Figure 16 shows a general cross-section and its context, going from a large outcrop in the north of Mawrth Vallis channel, through a crater, through the channel, and up to the southern side, through smallest color sub-units outcrops. We counted up to five different color sub-units ( $\delta 1$ to 5$)$ in the plateau, and two on the channel floor. Sub-unit $\delta 1$ is a Fe/Mg-clay rich location only visible in the south [as revealed by figure 6 in Loizeau et al., 2007], and $\delta 2$ covers a large part of the plateau shown in figure 16 , often covered by a dark mantle. The stronger erosion on the valley side shows $\delta 3$, an Fe/Mg-rich clay sub-unit, $\delta 4$, an Al-rich light blue sub-unit, and $\delta 5$, an $\mathrm{Fe} / \mathrm{Mg}$-rich clay sub-unit only visible on the left bank. To correlate the layering from one side to the other, we interpret the white layer above the terrace to correspond to the light blue layer $\delta 4$. In that case, the uppermost area in the northern section is covered by $\delta 3$ and $\delta 2$, at the potential MSL landing site location, and $\delta 1$ is eroded away or absent there. Dark material covers a large part of the valley sides, making difficult to connect the stratigraphy of the plateau to the one of the valley floor, but figure 14 suggests that clay-rich layered material exists beneath $\delta 5$.

The different outcrops of the same color sub-units that we follow along the crosssection, from one side of the Mawrth Vallis channel to the other, indicate a broad syncline at 
536 the present position of the outflow channel. This syncline is discussed in the view of the 537 topographic section of the channel thickness (see section 4.4). 


\section{Discussion}

4.1. Origin of the dome and lobate shape in the western part

One exceptional geomorphologic landform identified in our study comes from the dome visible in Figure 7. This dome displays a summital circular pit that does not look like an impact crater. Its slope (5\%), size (18 km diameter) and height $(400 \mathrm{~m})$ could correspond to a volcano such as a small shield volcano. By analogy, the Skjahlbreidur in Iceland, a typical shield volcano has such characteristics. In addition, it displays a summit cicular pit that does not look like an impact crater. However, the erosional aspect, the large presence of low temperature alteration material does not favor this hypothesis.

Mud volcanoes are known to exist in context of hydrothermal/volcanic activity together with large amount of clay material. The size of the dome in the Mawrth Vallis region is large compared to terrestrial mud volcanoes, but gentle slopes $\left(3-5^{\circ}\right)$ as well as difference of elevations reaching $200 \mathrm{~m}$ have been reported in Azerbaïdjan over $5 \mathrm{~km}$ large mud volcanoes [Hovland et al., 1997]. Offshore mud volcanoes appear to be more frequent [e.g. Yusifov anf Rabinowitz, 2004]. Observations of putative mud volcanoes on Mars have been reported [e.g. Skinner and Tanaka, 2007], although no definitive evidence has been found. Their origin usually comes from the superposition of mud-rich sediments in a hydrothermal context. In our case, we have the combination of a domical shape with a clay-rich material which favors this hypothesis relative to a classical volcano, but no additional evidence can certify this origin. Finally, in both hypotheses, this unique landform might suggest that a high thermal gradient existed at the time of the clay-rich unit formation.

The lobate tongue is enigmatic because of its negative relief (compared to the positive relief of a lava flow or a mud flow). Glaciers are usually able to explain such kind of erosion, because it vanishes by sublimation after erosion occurred, but the presence of a glacier at this exact location only would be a strong coincidence. A relationship with the dome and its central pit might be more likely. In absence of more precise mineralogical and subsurface information, we are not able to give a definitive origin for this tongue.

Finally, this dome and associated features are unique and enigmatic. They might tell either that volcanic/geothermal activity occurred at the time of the deposition, giving the potential for alteration guided by hydrothermal circulation, or that strong geothermal activity could have transformed part of the clay-rich unit into a mud volcano.

\subsection{Identification of a paleo-surface}

Figure 8 shows a large outcrop of a brown surface, stratigraphically deeper than the other sub-units of the clay-rich unit, and showing specific morphological characteristics. It displays several craters (up to $1 \mathrm{~km}$ in diameter) on its surface. Those craters are filled with 
light-toned layered material. Some of this material also remains visible on top of crater walls or directly on the flat brown surface: this morphology can be explained by the fact that the cratered brown unit (a3) was previously covered by clay-rich layers, which have been afterwards partially eroded, exhuming the brown-unit, and preserving only residual hills. Hence the brown unit corresponds to a paleo-surface of the early Mars: it was exposed to crater impacts before the deposition of meter-scale thick layers. Its presence indicates that the light-toned layers were once deposited at the surface of this region of Mars.

Similar outcrops are observed at the surface in other smaller outcrops in the northern and central parts of the overall region, as mapped in Figure 17a. These smaller outcrops, of which two HiRISE close-ups are shown in figures $17 \mathrm{~b}$ and $17 \mathrm{c}$, are also darker than the rest of the clay-rich unit, and have a brown, flat aspect, with the presence of some small light-toned buttes ( $\sim 100 \mathrm{~m}$ large), and several round shapes (up to $100 \mathrm{~m}$ wide), sometimes filled by light-toned material that we interpret as ancient craters of the paleo-surface. However, such large layered buttes as in Figure 8 are not present elsewhere. The paleo-surface displays less visible networks of small fractures in high resolution imagery than the other clay-rich outcrops (Fig. 11). All identified brown clay-rich outcrops shown in figure 17a are located at elevations from -3000 to $-3400 \mathrm{~m}$. Most of the outcrops of the paleo-surface are relatively small (less than $5 \mathrm{~km}$ across) with a tone close to the one of the dark material $(\mathrm{dm})$ partly covering the region. It is possible that every outcrop of the paleo-surface could not be identified and mapped in figure 17. Some brown outcrops might be present locally on Mawrth Vallis sides, from the mouth to the eastern part of the region, preferentially on the western channel side. Those exposures could possibly correspond to the same brown unit, but would need to be investigated at HiRISE resolution for confirmation, as the morphologic characteristics of this terrain are not resolvable with CTX or MOC imagery.

The brown surface is rich in Fe- or Mg-smectites at the location of Figure 8, but the estimation of the amount in volume of hydrated minerals is lower for this paleo-surface than for the other sub-units of the clay-rich unit [Poulet et al., 2008]. This brown surface contains approximately $20 \%$ of pyroxenes in contrast to other clay-rich sub-units, which have essentially no pyroxene [Poulet et al., 2008]. The sand cover and dark mantle are sparsely present on this outcrops on HiRISE imagery, hence the mafic minerals seen by OMEGA could be either a bulk component of the brown unit or simply a sand cover from the uppermost pyroxene-bearing dark mantle. Moreover, the brown sub-unit seems more indurated than the rest of the clay-rich unit; it does not waste away by erosion so easily. Therefore, we can propose two interpretations: (1) this brown surface could be the upper part of an underlying basaltic unit, partially altered by water, which could be the basement over which the clay-rich unit once deposited, or (2) it could constitute the top of a lower clay-rich unit, exposed to the surface, and later covered by a second period of deposition. In both cases, this observation shows that layers were deposited above the paleo-surface, but this does not 
611 indicate if the layers were already composed of clay-rich material at that time, or were altered 612 subsequently.

613 4.3. Thickness, extent, and geometry of deposition of the clay-rich unit

614 The presence of outcrops of the clay-rich unit on crater walls is a first indicator of the 615 thickness of the clay-rich unit. Craters such as those in figure 5 exhibit layers in their walls 616 over $\sim 150 \mathrm{~m}$ in thickness, and the floors of the craters are generally filled by dark material 617 such as pyroxene-bearing sand [Loizeau et al., 2007]. Any estimation of its thickness is an 618 estimation of a minimum value. The stratigraphically deeper brown sub-unit which was 619 observed in the northern and western part of the region is interpreted to be a paleo-surface 620 (mapped in Figure 17), because of the presence of filled craters, which formed at the surface 621 before being filled by sediments. The presence of other clay-rich sub-units below this brown 622 paleo-surface cannot be ruled out.

The sub-units are not always mapped from one part of the region to the other, but it seems that the sub-units ( $\beta 1$ to 4 ) from figure 10 and the sub-units ( $\gamma 1$ to 4 ) from figure 13 are the same, but appearing higher in elevation in figure 13 (around $-3000 \mathrm{~m}$ in figure 10 against from -2800 to $-2300 \mathrm{~m}$ in figure 13). It is also possible that the sub-units of the western part of the region (figure 8) are the western extension of the same sub-units, with the exception of the white-bluish thin sub-unit ( $\beta 3$ or $\gamma 3$ ). Hence, in the western (Fig. 8), and central parts (Fig. 10 and 13) of the region, we counted two to three main sub-units on top of a similar paleosurface, depending on location: 1$)$ on top a white/bluish Al-smectite rich sub-unit $(\alpha 1, \beta 1$, and

$631 \gamma 1$, which has been strongly eroded: its original thickness, before erosion and the later 632 deposition of the dark mantle, cannot be retrieved precisely but reaches more than $50 \mathrm{~m}$; 633 according to analyses of modal mineralogy from OMEGA data made by Poulet et al. [2008], 634 this sub-unit is mainly composed of montmorillonite and kaolinite (to a total of $40 \%$ ) and 635 hydroxides; 2) an orange or reddish Fe- or Mg-smectite rich sub-unit (generally $\sim 100 \mathrm{~m}$ thick, $636 \alpha 2, \beta 2$, and $\gamma 2$ ). This sub-unit comes to the surface between $-3500 \mathrm{~m}$ and $-2300 \mathrm{~m}$ in 637 elevation, from north to south, it would be principally made of nontronite and hydroxides, 638 reaching a total of $\sim 70 \%$ of hydrated minerals; and 3) a second white/bluish sub-unit, thinner 639 than the other two sub-units (< 30 m thick, $\beta 3$ and $\gamma 3$, seen in figures 10c, 11a, 13 and 15), 640 that seems not existent everywhere. A confirmation by CRISM of its composition would be 641 important regarding to the scenario of formation of the layered unit.

642 However, one can notice the stratigraphic differences between the scarp (Figure 7) and 643 the other outcrops of figures 8, 10 and 13. This observation suggests the presence of possible 644 lateral variations of the stratigraphy of the clay-rich unit: either compositional variations, 645 thickness variations or arrangement variations can happen from one part to another of the 646 clay-rich unit. 
On the other cross-sections (Fig. 15 and 16) covering terrains to the south, the visible sub-units generally outcrop higher in elevation, and the continuity of the northern sub-units is difficult to establish with the existent datasets because dark material covers the terrains located between the northern and southern studied outcrops. Furthermore, the brown paleosurface cannot be identified with certitude in the southern, thicker part of the clay-rich unit (see discussion in part 4.2); hence, it is not possible to connect the stratigraphy of the different outcrops of the clay-rich sub-units investigated in this study.

\subsection{Relation with the Mawrth Vallis channel}

655

656

657

658

659

660

661

662

663

664

665

666

667

668

669

670

671

672

673

674

675

676

677

678

679

680

681

682

683

In the eastern part, the main question for the geometry is the relationship with the outflow channel. Shallow dips toward the channel interior suggest that a deposition over the current outflow topography is possible, i.e. draping. However, the eastern side of the valley displays an eroded section of channel terraces (Fig.14) that should correspond to material deposited before the channel cut this area. Moreover, the lineations interpreted as erosional grooves have eroded the valley floor over the light-toned unit (Fig. 12), and the inclined layering at the channel floor does not show a draping geometry (Fig. 12 and 14). In addition, the thickness of the clay-rich unit would imply a strong smoothing of the streamlined islands and a filling of the grooves that is not observed.

Actually, the main argument for the hypothesis of a post-Mawrth Vallis deposition (as proposed by Howard and Moore [2007]) is the light blue layer in the valley side, which seems to be superimposed unconformably on other layers (Fig. 13), and the lack of obvious layers on the sides of the valley. This geometry questions the flow level of the outflow.

Assuming the channel thickness fits the lower level proposed (red line on Figure 12), it would only have cut the lower part of a valley that was pre-existent to the outflow. In this case, the broad syncline of the clay-rich unit could have been present before the outflow occurred; the layers would have been deposited nearly parallel to a previous topography, before the formation of the channel by the Mawrth Vallis flow. Then, the outflow could have been driven by this pre-existing topography, which could explain the strong changes of direction taken by the Mawrth Vallis channel from west to north (at $23^{\circ} \mathrm{N}, 18.5^{\circ} \mathrm{W}$ ) and downstream back from north to west (at $25.5^{\circ} \mathrm{N}, 18.5^{\circ} \mathrm{W}$ ).

On the other hand, a higher flow level of a full bank flow (blue line in Figure 12b) is ambiguous. It could involve a post-Mawrth Vallis formation from the dips measured in the upper part of the valley in the northern region. However, the fact that a series of layers $(\gamma 1$ to $\gamma 5$ ) is observed in the southern side of the valley's upper section implies that the erosion of the outflow is not responsible for the observed outcrops: in a post-Mawrth Vallis deposition, layers would have deposited after the valley formation and would follow the new topography created by the outflow rather than show this alternation of layers. Moreover, the outlet of Mawrth Vallis indicates a formation posterior to the dichotomy, because the channel cut the 
684 dichotomy boundary. This is difficult to reconcile with the observation of Figure 7 where layers are observed on the dichotomy boundary scarp, thus predating this period of erosion. In summary, the geometry of the clay-rich sub-units excludes the possibility for the deposition of the whole layered unit to have happened after the end of the outflow formation. However it does not exclude that the deposition of the top most layers, or the alteration of those layers, could have taken place after the erosion by the outflow.

\subsection{Origin of the layering}

The origin of the physical layering acquired during the deposition can be explained by different processes of deposition such as volcanic ash-fall, deposition of wind blown material, subaqueous sedimentation, impact ejecta [see also Loizeau et al., 2007a; Michalski and Noe

694 Dobrea, 2007]. The case for impact ejecta has been proposed for example in Terra Meridiani for the layering of sulfate-rich material [Knauth et al., 2005] whereas those outcrops display aeolian and subaqueous facies [Grotzinger et al., 2005]. This idea might apply for the layers in the Mawrth Vallis region too, at least as a contribution [Loizeau et al., 2007], but several observations do not support this idea as a major process. First, no HiRISE image shows the presence of extended layers of megabreccia such as those seen on the floor of Holden crater [Grant et al., 2007]. Second, hydrated minerals are observed in ejecta at Nili Fossae and Terra Thyrrena [Poulet et al., 2005, Mangold et al., 2007]. Figure 11 in Mangold et al. [2007] shows

702 that the ejecta of the $80 \mathrm{~km}$ large crater is not a suite of thin layers: it consists of lobate features with boulders and strongly disturbed material, different from the thin and regular layers observed in Mawrth Vallis. In contrast, the regular layering, with meter-scale layers over the whole region, with fine material easily removed by wind suggests a calm environment of deposition, which might be consistent with subaerial deposition of ash or dust, or sediments in a subaqueous environment.

\subsection{Relation between layers and compositional sub-units}

709

710

711

712

713

714

715

716

717

We have seen in section 3.1 that the compositional layering might not be similar to the physical layering. Examples usually suggest it might be very close to it (e.g. Figures 5), if not similar, when layers identified by colors follow the geometry of layers visible at any scale. However, local observations in HiRISE images (Fig. 12) show different color for similar layers. This suggests that the composition is not fixed with the deposition sequence, but that it occurred later. Thus, a way to consider both possibilities is to examine the timing of clay formation: before, during or after the deposition of the layers. If the compositional layering is different than the physical layers, it could only be possible by an alteration post-dating the deposition. 
718 5. Discussion : chronology of the layered unit formation and alteration

A chronology of formation of the clay-rich unit can be deduced from the hypotheses of formation discussed previously. An additional discussion about the link between deposition and alteration has to be led.

The outcrop of the western area of the region (figure 8) is a key area to understand the relative chronology of deposition of the layered-unit. Figure 18 illustrates the history deduced from this local area, which can be broadened to the rest of the region. The brown terrain existed at the surface of this region during a time long enough to be impacted by meteors as shown by the large craters (>100 m diameter) still present on the surface. We can not estimate this period of time because we do not know the exact age, and a lack of well-defined cratering rates for this early period makes it difficult to estimate an age [Neukum and Hiller, 1981]. Materials were then deposited on top of this cratered surface, and correspond nowadays to the clay-rich unit. Depending on location, this unit is subdivided in two or more sub-units of different composition. Later, a dark cover, rich in pyroxene and poorly indurated [Loizeau et al., 2007], was deposited over the whole region likely as a result of eolian processes (figure 18). Afterwards, erosion exhumed these layers at various level, creating the current outcrops, with, for example, the light-toned layered buttes inside the ancient craters on the brown surface in the western part of the region (figure 8).

The geometry might help us determine the timing of deposition of the layers. The upper series of layers, above the brown unit, is typically 100 to $300 \mathrm{~m}$ thick as seen in the western part of the region. The observed dips of the sub-units are close to the topography of the plateau, but was incised by the impact craters (Fig. 10 or 16) and few scarps (Fig. 6 at the dichotomy boundary), and Mawrth Vallis side (Fig. 14). This excludes the clay-rich unit as a basement exhumed by kilometers of erosion, but supports maximum erosion on the order of a few hundreds of meters over a series of layers deposited at the top of the crust. Moreover, the scarp at the dichotomy boundary (Fig. 6) shows that the deposition was anterior to the erosion of the dichotomy boundary which is usually estimated to be of the Late Noachian age [e.g. Frey, 2006; Watters et al., 2007], and not later than the Chryse Planitia filling in the Hesperian period. Indeed, the Chryse Planitia and MawrthVallis mouth were covered during the Hesperian period by deposits [Craddock et al, 1997; Tanaka et al., 2005], which lie unconformably over the clay rich unit at the contact between these plains and Mawrth Vallis mouth. This Chryse Planitia unit is an indurated, pyroxene-bearing surface, whose erosion might be responsible for the dark mantle observed throughout the region [Loizeau et al., 2007]. 
Three hypotheses about the relationship between the alteration and the deposition of the layered sub-units are to be considered: (1) the material might have been deposited as clayrich from the beginning, as a result of alteration, transport and sedimentation; (2) the alteration was acting at the same period as the deposition; (3) alteration occurred after the deposition of the whole layered unit. These three cases are discussed in the following paragraphs.

In the hypothesis of a pre-deposition alteration (Case 1), we do not know the original location of the alteration. If the sedimentation was subaqueous, processes of transport might have sorted fine grains in a quiet environment such as a lake. In that case, the deposition must have been very early to explain the lack of any basin in the current topography. Alternatively, wind can also sort grain and blow them away from their original location. In that case, this involves a much larger clay-rich unit somewhere else, something not observed anywhere on Mars yet. A problem in these hypotheses is how to create the composition differences between layers: wind action does not explain well differences in composition, and fluvial processes cannot easily explain this without mixing material.

Case 2 happened if, for example, sediments are modified by the surface environment, as observed on Earth. In this case, changes of surface temperatures and water activity through time might have involved differential leaching, conducive to different types of phyllosilicates: in such hypothesis the kaolinite/montmorillonite might be due to stronger alteration, as usually required for kaolinite which is a secondary alteration mineral [Meunier, 2002]. The material could have been collected into a basin, to explain the continuity of layers. Alternatively, pedo-diagenetic modifications during the burial of material could explain the geometry without involving an enclosed basin. This suggests that the surface environment was responsible of the weathering of rocks and the progressive deposition and modification of their alteration products under varying physical and chemical conditions at surface and near subsurface. The origin of the changes of these conditions is still to be determined.

Post-deposition alteration (Case 3) can also be proposed without any modification of the observed geometry according to two hypotheses. On one hand, layers might have been deposited initially in sub-units of different compositions, but not as clay. This is possible by deposition of volcanic ashes, or any sediment, with distinct initial compositions in the different sub-units. Then, they would have been altered into different alteration materials because of their differences in primary minerals, explaining the observed compositional layering from one sub-unit to the other. On the other hand, the difference in composition could have been due to differences in the environment of alteration after deposition, instead of differences in the material itself. This would be the case of an alteration due to the metamorphic activity of impact ejecta, heating by magmatism, or groundwater activity and diagenesis. Impact ejecta have been proposed to explain the dark mantling [Noe Dobrea et al., 2008]. However, some other bluish sub-units are buried beneath the reddish one (for example figure $15 \mathrm{~d}$ where we know the bluish material consists of Al-rich phyllosilicates, as observed 
793 by Wray et al. [2007]) disfavoring the case of a single episode with one gradient of alteration.

794 In the case of heating by magmatism or regular geothermal heat, the metamorphic gradient

795 would be the contrary: it would be higher with increasing depth and this creates the same

796 problem than the impact hypothesis because the alteration should have been smaller for

797 surficial material. This suggests that neither geothermal activity due to volcanism nor

798 diagenesis as a single process under a normal thermal gradient can fully explain the observed

799 composition layering, and that a post-depositional alteration would require pre-existing

800 compositional differences.

801 In summary, we find that the alternation of layers may be better explained either by

802 the progressive alteration under varying chemical conditions at the surface and near surface of

803 Mars during the formation of layers into a pedo-diagenetic environment (Case 2) or by

804 deposition of material of initial different compositions such as volcaniclastic sediments (ash,

805 pyroclastic accumulations), wind blown or aqueous sediments (Case 3), that were 806 subsequently altered by processes such as groundwater activity (diagenesis or

807 hydrothermalism), and/or shallow water environment (pedogenesis). This last case is also

808 consistent with the likely preservation of non-clay material in the clay-rich unit as suggested

809 by Michalski and Fergason [2008] from TES data, because initial volcanic material might

810 have not been altered completely. These two cases strongly favor the role of in situ alteration

811 rather than transported clays, a characteristic to consider in the selection of future landing

812 sites for in situ missions, compared to sites where clays might have been transported. 


\section{6. Conclusion}

814 The combined use of spectroscopic data, high resolution color data and high resolution

815 DTM provides a unique opportunity to study the geometry of the Mawrth Vallis thick clay816 rich unit. It revealed the sub-division of the clay-rich unit into color sub-units, formed by 817 groups of tens of single layers of similar color. OMEGA and HRSC show a link between 818 color and composition, with white/blue terrain rich in Al-smectites, and yellow, pink, orange, 819 red and brown terrains rich in Fe- or $\mathrm{Mg}$-smectites.

820 Assuming the compositional layering visible by the presence of the color sub-units is

821

822

823

824

825

826

827

828

829

830

831

832

833

834

835

836

837

838

839

840

841

842

843

844

845

846

847

848

849 directly linked to geological formations, it is possible to retrieve the regional stratigraphy of the clay-rich unit, and improve the understanding of its processes of formation.

We counted up to five successive sub-units on the southern part of the plateau around Mawrth Vallis, but other heavily eroded sub-units appear down to the floor of the outflow channel, indicating a possible larger number of sub-units. Most outcrops of this clay-rich unit are heavily eroded and fractured into meter-scale blocks. The outcrop of the clay unit at the scarp of the dichotomy boundary indicates a formation prior to the dichotomy boundary erosion. Moreover, a nearby domical edifice raises the question of the implication of volcanism in this region.

Observations of strongly eroded clay-rich sub-units and grooves on the Mawrth Vallis floor, and of clay-rich outcrops along a cliff at the dichotomy boundary would imply that the deposition of the large majority of the layered unit predates the formation of the Mawrth Vallis channel and the dichotomy erosion, not excluding the possibility of shallow deposition and alteration since those episodes.

This study also revealed the presence of a brown clay-rich paleo-surface, but with lower amount of hydrated minerals than the rest of the clay-rich unit, which lies on top of this brown paleo-surface. The material of the layered unit was deposited in thin layers $(\sim 1 \mathrm{~m}$ or less) on top of this paleo-surface.

We propose two main hypotheses of formation of the clay-rich unit:

1) Non hydrated material was deposited by wind or water in the region, by sequences, in thin layers. The source of this material changed sometimes in composition, building up different sub-units. This material has been later altered by groundwater activity or shallow water environment, preserving the layers and the differences in composition between the sub-units, and altering superficially the paleo-surface.

2) Alteration occurred progressively at martian surface and near-surface, and the products of alteration were regularly deposited in the Mawrth Vallis region, where the paleo-surface was superficially altered. Changes in chemical conditions at the surface could explain the formation of different compositional sub-units as in pedo-diagenetic environments. 
850 Geometric observations of the clay-rich sub-units tend to show that the clay-rich unit 851 has been deposited over the region as a thick deposition ( $>300 \mathrm{~m}$ thick) over a non-horizontal

852 paleo-surface, and that at the end of the deposition, the regional topography was close to the 853 present one.

854

855

856

857

858

859

860

\section{Acknowledgments}

We acknowledge the efforts of the OMEGA and HRSC Co-Investigator Team members and their associates who have contributed to this investigation in the preparatory phase and in scientific discussions within the teams, and particularly Joseph Michalski for his careful reading of the manuscript. We thank all engineers and scientists who made the HRSC

and OMEGA experiments possible, as well as the ESA/Mars Express project. We also 861 acknowledge the MOC/MGS, THEMIS/Mars Odyssey, CTX/MRO and HiRISE/MRO teams.

862 Careful and constructive reviews by Janice Bishop and an anonymous reviewer helped to a 863 significant improvement of the manuscript. The authors are granted by the Centre National

864 d'Etudes Spatiales (CNES) and the Programme National de Planétologie (PNP) of Institut 865 National des Sciences de l'Univers (INSU). 
Ansan, V.; Mangold, N.; Masson, P., Gaihlardis, E.; and G. Neukum. 2008. Topography of valley networks on Mars from the Mars Express High Resolution Stereo Camera Digital Elevation Models. Journal of Geophysical Research, Volume 113, Issue E7, CiteID E07006. DOI: 10.1029/2007JE002986.

Albertz, J., Attwenger, M., Barret, J., Casley, S., Dominger, P., Dorrer, E., Ebner, H., Gehrke, S., Giese, B., Gwinner, K., Heipke, C., Howington-Kraus, E., Kirk, R. L., Lehmann, H., Mayer, H., Muller, J., Oberst, J., Ostrovskiy, A., Renter, J., Reznik, S., Schmidt, R., Scholten, F., Spiegel, M., Stilla, U., Wählisch, M., Neukum, G., and the HRSC CoI-Team. 2005. HRSC on Mars Express - Photogrammetric and cartographic research. Photogram. Eng. Rem. Sens. 71 (10), 1153-1166.

Bibring, J.-P.; Soufflot, A.; Berthé, M.; Langevin, Y.; Gondet, B.; Drossart, P.; Bouyé, M.; Combes, M.; Puget, P.; Semery, A.; Bellucci, G.; Formisano, V.; Moroz, V.; Kottsov, V.; Bonello, G.; Erard, S.; Forni, O.; Gendrin, A.; Manaud, N.; Poulet, F.; Poulleau, G.; Encrenaz, T.; Fouchet, T.; Melchiori, R.; Altieri, F.; Ignatiev, N.; Titov, D.; Zasova, L.; Coradini, A.; Capacionni, F.; Cerroni, P.; Fonti, S.; Mangold, N.; Pinet, P.; Schmitt, B.; Sotin, C.; Hauber, E.; Hoffmann, H.; Jaumann, R.; Keller, U.; Arvidson, R.; Mustard, J.; Forget, F. 2004. OMEGA: Observatoire pour la Minéralogie, l'Eau, les Glaces et l'Activité, In: Mars Express: the scientific payload. Ed. by Andrew Wilson, scientific coordination: Agustin Chicarro. ESA SP-1240, Noordwijk, Netherlands: ESA Publications Division, ISBN 92-9092-556-6, 2004, p. 37 - 49.

Bibring, Jean-Pierre; Langevin, Yves; Mustard, John F.; Poulet, Fran $<$ A. $>$ ç. $</$ A. $>$ ois; Arvidson, Raymond; Gendrin, Aline; Gondet, Brigitte; Mangold, Nicolas; Pinet, P.; Forget, F. 2006. Global Mineralogical and Aqueous Mars History Derived from OMEGA/Mars Express Data. Science, Volume 312, Issue 5772, pp. 400-404. Doi : 10.1126/science.1122659.

Bishop, J. L.; C. M. Pieters, and J. O. Edwards (1994) Infrared spectroscopic analyses on the nature of water in montmorillonite. Clays Clay Miner. 42, 701-715.

Bishop J. L., Madejova J., Komadel P., and Froeschl H. (2002) The Influence of Structural $\mathrm{Fe}, \mathrm{Al}$ and $\mathrm{Mg}$ on the Infrared $\mathrm{OH}$ Bands in Spectra of Dioctahedral Smectites. Clay Miner. 37, 607-616.

Bishop, J. L.; Noe Dobrea, E.; McKeown, N.; Mustard, J. F.; Ehlmann, B. L.; Milliken, R. E.; Murchie, S. L.; Bibring, J.; Poulet, F.; Malaret, E.; Hash, C.; CRISM Team. 2007. Layering of Al- and Fe/Mg-phyllosilicates in Western Mawrth Vallis, Mars, and Implications for Aqueous Processes During the Noachian Period. American Geophysical Union, Fall Meeting 2007, abstract \#P13D-1559.

Bishop, J. L.; Noe Dobrea, E.; McKeown, N.; Parente, M.; Ehlmann, B. L.; Michalski, J. R.; Milliken, R. E.; Poulet, F.; Swayze, G. A.; Mustard, J. F.; Murchie, S. L.; Bibring, J.-P. 
905

906

907

908

909

910

911

912

913

914

915

916

917

918

919

920

921

922

923

924

925

926

927

928

929

930

931

932

933

934

935

936

937

938

939

940

941

942

943

(2008) Phyllosilicate Diversity and Past Aqueous Activity Revealed at Mawrth Vallis, Mars. Science 321, 830. DOI: 10.1126/science.1159699.

Bishop, J. L., M. D. Lane, M. D. Dyar, and A. J. Brown. 2008b. Reflectance and emission spectroscopy study of four groups of phyllosilicates: Smectites, kaolinite-serpentines, chlorites and micas. Clay Miner. 43, 35-54.

Clark, R.N., Swayze, G.A., Wise, R., Livo, E., Hoefen, T., Kokaly, R., Sutley, S.J., 2007, USGS digital spectral library splib06a: U.S. Geological Survey, Digital Data Series 231.

Clark, Roger N.; King, Trude V. V.; Klejwa, Matthew; Swayze, Gregg A.; Vergo, Norma (1990) High Spectral Resolution Reflectance Spectroscopy of Minerals, Journal of Geophysical Research (ISSN 0148-0227), vol. 95, p. 12653-12680 (1990)

Craddock, Robert A.; Crumpler, Larry S.; Aubele, Jayne C.; Zimbelman, James R. (1997) Geology of central Chryse Planitia and the Viking 1 landing site: Implications for the Mars Pathfinder mission. Journal of Geophysical Research, Volume 102, Issue E2, p. 4161-4184. DOI: 10.1029/97JE00058.

Duxbury, T. C., Kirk, R. L., Archinal, B. A., and Neumann, G. A., 2002. Mars geodesy/cartography working group recommendation on Mars cartographic constants and coordinate systems. Symposium on Geospatial Theory. Processing and Application. Ottawa.

Farrand, W. H.; $\quad$ Rice, J. W.; Glotch, T. D.; Hurowitz, J. A., $2007 . \quad$ Hyperspectral, Multispectral, and Textural Analysis of the Mawrth Vallis Layered Terrain, Seventh International Conference on Mars, held July 9-13, 2007 in Pasadena, California, LPI Contribution No. 1353, p. 3304.

Frey, H. V. (2006), Impact constraints on the age and origin of the lowlands of Mars, Geophys. Res. Lett., 33, L08S02, doi:10.1029/2005GL024484.

Grant, J. A.; Irwin, R. P.; Grotzinger, J. P.; Milliken, R. E.; Tornabene, L. L.; McEwen, A. S.; Weitz, C. M.; Squyres, S. W.; Glotch, T. D.; Thomson, B. J.; Hirise Team. 2007. Impact and Aqueous Stratigraphy in Holden Crater as Revealed by HiRISE. Seventh International Conference on Mars, held July 9-13, 2007 in Pasadena, California, LPI Contribution No. 1353, p.3229

Grotzinger, J. P.; $\quad$ Arvidson, R. E.; $\quad$ Bell, J. F.; Calvin, W.; Clark, B. C.; Fike, D. A.; Golombek, M.; Greeley, R.; Haldemann, A.; Herkenhoff, K. E.; Jolliff, B. L.; Knoll, A. H.; $\quad$ Malin, M.; $\quad$ McLennan, S. M.; $\quad$ Parker, T.; $\quad$ Soderblom, L.; $\quad$ SohlDickstein, J. N.; Squyres, S. W.; Tosca, N. J.; Watters, W. A. 2005. Stratigraphy and sedimentology of a dry to wet eolian depositional system, Burns formation, Meridiani Planum, Mars. Earth and Planetary Science Letters, Volume 240, Issue 1, p. 11-72. DOI: 10.1016/j.epsl.2005.09.039.

Gwinner, K., Scholten, F., Jaumann, R., Roatsch, T., Oberst, J., Neukum, G., 2007. Global mapping of Mars by systematic derivation of Mars Express HRSC high-resolution digital elevation models and orthoimages. ISPRS Commission IV, Working Group 9, 
958

959

960

961

962

963

964

965

966

967

968

969

970

971

972

973

974

975

976

977

978

979

980

981

Extraterrestrial Mapping Workshop "Advances in Planetary Mapping 2007, Houston, Texas.

Hovland, M., A. Hill and D. Stokes. 1997. The structure and geomorphology of the Dashgil mud volcano, Azerbaijan. Geomorphology, 21 (1), 1-15.

Howard, A. D.; Moore, J. M. 2007. The Light-toned Sediments in and near Lower Mawrth Vallis May be a Drape Deposit. 38th Lunar and Planetary Science Conference, (Lunar and Planetary Science XXXVIII), held March 12-16, 2007 in League City, Texas. LPI Contribution No. 1338, p.1339.

Jaumann, R., Neukum, G., Behnke, T., Duxbury, T. C., Floohrer, J., Gasselt, S. V., Giese, B., Gwinner, K.,. Hauber, E., Hoffmann, H., Hoffmeinster, A., Köhler, U., Matz, K-D., McCord, T. B., Mertens, V., Oberst, J.., Pischel, R., Rei $\square$, D., Ress, B., Roasch, T., Saiger, P., Scholten, F., Schwarz, G., Stephan, K., Wählisch. M., and the HRSC CoInvestigator Team, 2007. The high resolution stereo camera (HRSC) experiment on Mars express: Instrument aspects and experiment conduct from interplanetary cruise through the nominal mission. Planetary and Space Science 55, p. 928-952 ; doi:10.1016/j.pss.2006.12.003.

Knauth, L. Paul; Burt, Donald M.; Wohletz, Kenneth H. 2005. Impact origin of sediments at the Opportunity landing site on Mars. Nature, Volume 438, Issue 7071, pp. 1123-1128. DOI: $10.1038 /$ nature04383.

Loizeau, D.; Mangold, N.; Poulet, F.; Bibring, J.; Langevin, Y.; Hauber, E.; Neukum, G., 2006. Phyllosilicates in the Mawrth Vallis Region, Mars, as Seen by OMEGA and HRSC/Mars Express. American Geophysical Union, Fall Meeting 2006, abstract \#P23D0093.

Loizeau, D.; Mangold, N.; Poulet, F.; Bibring, J.-P.; Gendrin, A.; Ansan, V.; Gomez, C.; Gondet, B.; Langevin, Y.; Masson, P.; Neukum, G., 2007. Phyllosilicates in the Mawrth Vallis region of Mars. Journal of Geophysical Research, Volume 112, Issue E8, CiteID E08S08. DOI: 10.1029/2006JE002877.

Loizeau, D.; Mangold, N.; Poulet, F.; Bibring, J.-P.; Langevin, Y.; Ansan, V.; Masson, P.; Neukum, G.; Omega Team; HRSC Team. 2007. Stratigraphic Correlation Between the Clays of the Region of Mawrth Vallis as Detected by OMEGA, and HRSC Color Images and DTM. Seventh International Conference on Mars, held July 9-13, 2007 in Pasadena, California, LPI Contribution No. 1353, p.3131.

Malin, Michael C.; $\quad$ Bell, James F.; $\quad$ Cantor, Bruce A.; $\quad$ Caplinger, Michael A.; Calvin, Wendy M.; $\quad$ Clancy, R. Todd; $\quad$ Edgett, Kenneth S.; $\quad$ Edwards, Lawrence; Haberle, Robert M.; James, Philip B.; Lee, Steven W.; Ravine, Michael A.; Thomas, Peter C.; Wolff, Michael J. 2007. Context Camera Investigation on board the Mars Reconnaissance Orbiter. Journal of Geophysical Research, Volume 112, Issue E5, CiteID E05S04. DOI: 10.1029/2006JE002808 
982

983

984

985

986

987

988

989

990

991

992

993

994

995

996

997

998

999

1000

1001

1002

1003

1004

1005

1006

1007

1008

1009

1010

1011

1012

1013

1014

1015

1016

1017

1018

1019

1020

Malin, Michael C.; Edgett, Kenneth S. 2001. Mars Global Surveyor Mars Orbiter Camera: Interplanetary cruise through primary mission. Journal of Geophysical Research, Volume 106, Issue E10, p. 23429-23570. DOI: 10.1029/2000JE001455.

Malin, M. C.; Danielson, G. E.; Ingersoll, A. P.; Masursky, H.; Veverka, J.; Ravine, M. A.; Soulanille, T. A. 1992. Mars Observer Camera. Journal of Geophysical Research, Volume 97, Issue E5, p. 7699-7718.

Mangold, N., Poulet, F., Mustard J. F., J.-P. Bibring, B. Gondet, Y. Langevin, V. Ansan, Ph. Masson, C. Fassett, J. W. Head III, H. Hoffmann, and G. Neukum, 2007, Mineralogy of the Nili Fossae region with OMEGA/Mars Express data: 2. Aqueous alteration of the crust, J. Geophys. Res., 112, E08S04.

McCord, T. B.; Adams, J. B.; Bellucci, G.; Combe, J.-P.; Gillespie, A. R.; Hansen, G.; Hoffmann, H.; Jaumann, R.; Neukum, G.; Pinet, P.; Poulet, F.; Stephan, K. 2007. Mars Express High Resolution Stereo Camera spectrophotometric data: Characteristics and science analysis. Journal of Geophysical Research, Volume 112, Issue E6, E06004. DOI: 10.1029/2006JE002769

McEwen, Alfred S.; $\quad$ Eliason, Eric M.; $\quad$ Bergstrom, James W.; $\quad$ Bridges, Nathan T.; Hansen, Candice J.; $\quad$ Delamere, W. Alan; $\quad$ Grant, John A.; $\quad$ Gulick, Virginia C.; Herkenhoff, Kenneth E.; Keszthelyi, Laszlo; Kirk, Randolf L.; Mellon, Michael T.; Squyres, Steven W.; Thomas, Nicolas; Weitz, Catherine M. 2007. Mars Reconnaissance Orbiter's High Resolution Imaging Science Experiment (HiRISE). Journal of Geophysical Research, Volume 112, Issue E5, CiteID E05S02. DOI: 10.1029/2005JE002605

McKeown, N. K.; $\quad$ Bishop, J. L.; $\quad$ Noe Dobrea, E.; $\quad$ Ehlmann, B. L.; $\quad$ Mustard, J. F.; Murchie, S. L.; Bibring, J.; Poulet, F.; Silver, E.; Malaret, E.; Hash, C.; CRISM Team. 2007. Phyllosilicate identification in Mawrth Vallis: an analysis of CRISM multispectral data and targeted images FRT4ECA and HRS307A. American Geophysical Union, Fall Meeting 2007, abstract \#P13D-1558.

Melosh, H. J. 1989. Impact cratering: A geologic process. Research supported by NASA. New York, Oxford University Press (Oxford Monographs on Geology and Geophysics, No. 11), 1989, 253 p.

Meunier, Alain. 2002. Argiles. Contemporary Publishing International, GB Science Publisher, $435 \mathrm{p}$.

Michalski, J. R.; and E.Z. Noe Dobrea. 2007. Evidence for a sedimentary origin of clay minerals in the Mawrth Vallis region, Mars. Geology, October 2007; v. 35; no. 10; p. 951954; doi: 10.1130/G23854A.1

Michalski, J. R.; and R. Fergason. 2008. Composition and thermal inertia of the Mawrth Vallis region of Mars from TES and THEMIS data. Submitted to Icarus.

Neukum, G., and K. Hiller (1981), Martian Ages, J. Geophys. Res., 86(B4), 3097-3121.

Neukum, G., Jaumann, R., and HRSC Co-Investigator Team. 2004. HRSC: The high Resolution Stereo camera of Mars Express. ESA Special Publication. SP-1240. 
1021

1022

1023

1024

1025

1026

1027

1028

1029

1030

1031

1032

1033

1034

1035

1036

1037

1038

1039

1040

1041

1042

1043

1044

1045

1046

1047

1048

1049

1050

1051

1052

1053

1054

1055

1056

1057

1058

1059

Noe Dobrea, E. Z.; Bishop, J. L.; McKeown, N. K.; Swayze, G.; Michalski, J. R.; Poulet, F.; Bibring, J.-P.; $\quad$ Mustard, J. F.; $\quad$ Ehlmann, B. L.; $\quad$ Arvidson, R. E.; $\quad$ Morris, R. V.; Murchie, S. L.; McEwen, A. S.; Malaret, E.; Hash, C.; Crism Team. 2008. Clay Bearing Units in the Region Around Mawrth Vallis: Stratigraphy, Extent, and Possible Alteration Fronts. 39th Lunar and Planetary Science Conference, (Lunar and Planetary Science XXXIX), held March 10-14, 2008 in League City, Texas. LPI Contribution No. 1391., p.1077.

Poulet, F.; $\quad$ Bibring, J.-P.; $\quad$ Mustard, J. F.; $\quad$ Gendrin, A.; $\quad$ Mangold, N.; $\quad$ Langevin, Y.; Arvidson, R. E.; Gondet, B.; Gomez, C. 2005. Phyllosilicates on Mars and implications for early martian climate. Nature, Volume 438, Issue 7068, pp. 623-627. DOI: $10.1038 /$ nature 04274

Poulet, F.; Chevrier, V.; Bibring, J.; Langevin, Y.; Gondet, B. 2007. Modal Mineralogy Of The Martian Phyllosilicate-rich Terrains And Implication For Their Formation. American Geophysical Union, Fall Meeting, abstract \#P11E-07.

Poulet, F., Mangold, N., Loizeau, D., Bibring, J.-P., Langevin, Y., Michalski, J. R., Gondet, B. 2008. New evidence of significant abundance of clay minerals on Mars. A\&A 487, L41-L44. DOI: 10.1051/0004-6361:200810150.

Retallack, G. J., Bestland, E. A., Fremd, T. J. 2000. Eocene and Oligocene paleosols of Central Oregon, GSASpe paper 344, 192pp.

Ruff, S. W., and P. R. Christensen (2002), Bright and dark regions on Mars: Particle size and mineralogical characteristics based on Thermal Emission Spectrometer data, J. Geophys. Res., 107(E12), 5127, doi:10.1029/2001JE001580.

Scholten, F., Gwinner K., Roasch, T., Matz, K.-D., Wählisch, M., Giese, B., Oberst, J., Jaumann, R., Neukum, G., and HRSC Co-Investigator Team, 2005. Mars express HRSC Data Processing. Photogrammetric Eng. Remote Sensing 71 (10), 1143-1152.

Seidelmann, P. K., Abablakin, V. K., Bursa, M., Davies, M.E., De Bergh, C., Leiske, J. H., Oberst, J., Simon, J. L., Standish, E. M., Stooke, P., and Thomas, P. C., 2002. Report of the IAU/IAG working group on cartographic coordinates and rotational elements of the planets and satellites: 2000. Celest. Mech. Dyn. Astron. 82, 83-110.

Skinner, Jr, J. A. and K. L. Tanaka. 2007. Evidence for and implications of sedimentary diapirism and mud volcanism in the southern Utopia highland-lowland boundary plain, Mars. Icarus, 186, (1), 41-59.

Smith, D. E., 1999. The gravity field of Mars: results from mars Glolal Surveyor. Science 286, 94-97.

Smith, D. E., Zuber, M. T., Solomon, S.C., Phillips, R. J., Head, J. W., Garvin, J. B., Banerdt, W. B., Muhleman. D. O., Pettengill, G. H., Neumann, G. A., Lemoine, F. G., Abshire, J. B., Aharonson, O., Brown, C.D.,. Hauck, S. A., Ivanov, A. B., McGovern, P. J., Zwally, H. J., and Duxbury, T. C., 1999. The global topography of Mars and Implications for surface evolution. Science 284, 1495-1503. 
Spiegel, M., Schmidt, R., Stilla, U., Neukum, G., 2007. Improvement of Exterior Orientation of Mars Eypress HRSC Imagery Using a Photogrammetric Block. LPSC XXXVII, Abstract \#1608. Lunar and Planetary Institute, Houston.

Tanaka, Kenneth L.; Skinner, James A., Jr., Hare, Trent M. 2005. Geologic map of the Northern Plaines of Mars. U. S. Geological Survey, Scientific Investigation Map 2888.

Watters, Thomas R.; McGovern, Patrick J.; Irwin, Rossman P., III. 2007. Hemispheres Apart: The Crustal Dichotomy on Mars. Annual Review of Earth and Planetary Sciences, vol. 35, Issue 1, p.621-652. DOI: 10.1146/annurev.earth.35.031306.140220.

Wray, J. J.; Squyres, S. W.; Ehlmann, B. L.; Mustard, J. F.; Hirise Team, 2007. Meter-Scale Morphology and Stratigraphy of Phyllosilicate-rich Outcrops in Mawrth Vallis. Seventh International Conference on Mars, held July 9-13, 2007 in Pasadena, California, LPI Contribution No. 1353, p.3119.

Wray, J. J.; Ehlmann, B. L.; Squyres, S. W.; Mustard, J. F.; Kirk, R. L. (2008) Compositional stratigraphy of clay-bearing layered deposits at Mawrth Vallis, Mars. Geophysical Research Letters, Volume 35, Issue 12, CiteID L12202. DOI: 10.1029/2008GL034385.

Yusifov, M. and P. D. Rabinowitz. 2004. Classification of mud volcanoes in the South Caspian Basin, offshore Azerbaijan. Marine and Petroleum Geology, 21 (8), 965-975. 


\section{FIGURES' CAPTIONS:}

Figure 1: Mosaic of HRSC RGB images of the Mawrth Vallis region (MEx orbits \#1293, 1326 and 1337) superimposed on HRSC panchromatic nadir images of the same orbits. The white boxes indicate the location of the close-ups of figures 3 and 5. The yellow boxes indicate the location of the figures with cross-sections $6,10,13$ and 16.

Figure 2: (a): Ensemble of the 3D object points for which the elevation has been retrieved through HRSC stereoscopic images, the white zones are void of points, the color code correspond to the elevation. (b): The resultant HRSC DTM, with spatial resolution of 40 $\mathrm{m} /$ pixel. (c): Close-up of the 3D object points map. A void of points happens mainly on the flat dark mantle and on crater floors. (d): Close-up of figure 1 for the same area as (c). HRSC DTM height contours have been added with an interval of $100 \mathrm{~m}$.

Figure 3: Four close-ups of figure 1. Left: A same regional color scale has been applied for the HRSC RGB composite for the 4 areas shown in this figure. Middle: OMEGA detection of the $1.93 \mu \mathrm{m}$ band superimposed on the HRSC RGB composite. Right: OMEGA detection of the 2.20 and $2.29 \mu \mathrm{m}$ bands, in green and red respectively. The difference between the size of the OMEGA detection pixels from one area to the other and inside an area comes from the different resolution of the different OMEGA orbits covering the region.

Figure 4: Comparison of two Al-bearing phyllosilicates (kaolinite and montmorillonite from the USGS spectral library [Clark et al., 2007]) and a Fe-bearing smectite (nontronite from Bishop et al. [2002]) laboratory spectra in the near infrared. An estimation of the HRSC color channels' bandwidths that we used in this study is indicated between dashed lines. The principal mineral absorption bands mentioned in the text are also pointed out by arrows.

Figure 5: a) Close-up of figure 1 of two kilometer-size craters (see figure 1 for location). CTX images have been superimposed on the HRSC nadir images in order to improve the spatial resolution. The elevation is indicated by height contours (interval is 50 $\mathrm{m})$. North is up. The white box indicates the location of the down-left close-up of the figure.

b) Wall of one of the above craters. This image has been obtained by superposing HiRISE image PSP_004052_2045 (28.6 cm/pixel), HRSC RGB composite image, and HiRISE RGB composite image (PSP_004052_2045) for the central strip. The white box indicates the location of figure $\mathrm{c}$.

c) HiRISE RGB composite image PSP_004052_2045. The groups of layers of different colors define different sub-units. North is up, light comes from the south-west. The sketch to the left illustrates the different sub-units of this close-up. 
Figure 6: a) Close-up of figure 1, on the plateau in the western part of the region, between Chryse Planitia, to the north-west, and the large central crater of figure 1, to the south-east. The white boxes indicate the location of the 3 close-ups: (b), figure 7 and figure 8 . The dashed white line indicates the approximate location of a potential MSL landing-site [Michalski and Fergason, 2008].

b) Close-up on the scarp between the plateau and a basin on the border of Chryse Planitia. HRSC DTM height contours are displayed with an interval of $100 \mathrm{~m}$.

c) Close-up on the cross-section of the scarp presented in (d).

d) Constrained cross-section of the upper-figure derived from the HRSC DTM and the color imagery.

Figure 7: a) Close-up on a dome on the plateau (see figure 6 for the location). HRSC DTM height contours are displayed with an interval of $50 \mathrm{~m}$. The white box indicates the location of the zoom in c).

b) same close-up, but showing the OMEGA detection of the $1.93 \mu \mathrm{m}$ band.

c) CTX image showing the summital circular pit (rim indicated by the white dotdashed line) and the lobate feature (boundaries indicated by the white dashed line) originating from it. HRSC RGB composite is superimposed, and HRSC DTM height contours are displayed with an interval of $25 \mathrm{~m}$.

Figure 8: a) Close-up of figure 6 on an outcrop with four distinct colors (from west to east, brown, reddish, white and black). CTX and MOC narrow angle images have been added, when available, to improve the spatial resolution. The white line indicates the location of the cross-section at the bottom of the figure. HRSC DTM height contours are displayed with an interval of $50 \mathrm{~m}$. The different sub-units are indicated by $\alpha 1, \alpha 2$, and $\alpha 3$, the dark mantle by $\mathrm{dm}$.

b) Close-up of the top-left image on some of the light-toned layered buttes surrounded by the brown material. A simple sketch at the top shows how those light-toned layered buttes are eroded light-toned layered material deposited on top of ancient craters of the brown material.

c) Constrained cross-section derived from the HRSC DTM and the color imagery. Three sub-units can explain the morphology of this area, locally covered by a dark mantling on the top.

Figure 9: Perspective view (3x vertical exaggeration) of the western part of the Mawrth Vallis region (Figure 6) towards the south. The sub-units of figure 8 are indicated.

Figure 10: a) Close-up of figure 1, on a large plateau, south of the Mawrth Vallis mouth. The white boxes indicate the location of the 2 close-ups (b) and (c) on the right. The 
1154 white line indicates the location of the downer cross-section. The dashed white line indicates 1155 the approximate location of a potential MSL landing-site [Michalski and Fergason, 2008].

1156 The two yellow boxes indicate the locations of the HiRISE close-ups in figure 11. HRSC 1157 DTM height contours are displayed with an interval of $200 \mathrm{~m}$.

1158 Close-ups (b) and (c) have been made by superposing HRSC RGB composite image 1159 on CTX and HiRISE images. HRSC DTM height contours are displayed with an interval of $116050 \mathrm{~m}$. (b): crater showing color layering sub-units on its wall. (c): strongly eroded flat terrain, 1161 different sub-units are exhumed, resulting in this complex morphology. The different sub1162 units are indicated by $\beta 1, \beta 2, \beta 3$ and $\beta 4$.

1163 d) Constrained cross-section derived from the HRSC DTM and the color imagery.

1164

1165

1166

1167

1168

1169

1170

1171

1172

1173

1174

1175

1176

1177

1178

1179

1180

1181

1182

1183

1184

1185

1186

1187

1188

1189

1190

1191
Figure 11: Two close-ups of the HiRISE image PSP_002351_2050. Locations are indicated in figure 10. Figure (a) is the northest one.

a): a small cliff ( $\sim 30 \mathrm{~m}$ high) on the Mawrth Vallis plateau.

b): eroded layers near a layered butte on the plateau. The limits of the different layers are indicated by white arrows.

Fig 12: a) Part of the Mawrth Vallis channel. HRSC DTM height contours are displayed with an interval of $200 \mathrm{~m}$. The white lines indicate the location of the three crosssections of image $b$.

b) Three cross-sections along the Mawrth Vallis channel. Dashed lines indicate supposed levels of outflows, derived from the presence of slope breaks and terraces along the sides.

c) HRSC color image close-up centered on a streamlined island. Lineations are indicated by " $\ell$ ' and images (d) and (e) by yellow boxes.

d) Close-up of color HiRISE image PSP_006465_2045 at the base of a streamlined island of Mawrth Vallis. The red arrow shows the direction of the slope.

e) HRSC RGB composite image superimposed on a close-up of HiRISE image PSP_006465_2045 at the base of a streamlined island of Mawrth Vallis. The red arrow shows the direction of the slope.

Figure 13: a) Close-up of figure 1, on the western flank of the Mawrth Vallis channel. The white line indicates the location of the downer cross-section. HRSC DTM height contours are displayed with an interval of $100 \mathrm{~m}$. This plateau corresponds to one of the potential MSL landing site [Michalski and Fergason, 2008].

b) Constrained cross-section derived from the HRSC DTM and the color imagery. The different sub-units are indicated by $\gamma 1, \gamma 2, \gamma 3$ and $\gamma 4$. 
Figure 14: a) and b) close-up of figure 1 in the central part of the region, on the floor and the eastern flank of Mawrth Vallis. The white boxes in a) indicate the location of the images c) and d). HRSC DTM height contours are displayed with an interval of $50 \mathrm{~m}$ in b).

c) Composite of CTX and MOC narrow angle images, HRSC RGB image is superimposed.

d) HiRISE image PSP_001454_2030 located at the base of Mawrth Vallis eastern flank. The red arrow shows the direction of the slope.

Figure 15: a) Constrained cross-section corresponding to figure b). The topography is derived from the HRSC DTM.

b) Close-up of a CTX image of a crater on the flank of Mawrth Vallis. The location is indicated in figure 12a. HRSC RGB composite image is superimposed, and HRSC DTM height contours are displayed with an interval of $50 \mathrm{~m}$. The white line indicates the location of the cross-section showed in a).

c) Close-up of a CTX image on an outcrop on the flank of Mawrth Vallis. The location is indicated in figure 12a. HRSC RGB composite image is superimposed, and HRSC DTM height contours are displayed with an interval of $50 \mathrm{~m}$. The white line indicates the location of the cross-section showed in d).

d) Constrained cross-section corresponding to figure c). The topography is derived from the HRSC DTM.

Figure 16: a) Close-up of figure 1 (north is to the left), in the southern part of the region, crossing the Mawrth Vallis channel. The white line indicates the location of the crosssection at the bottom of the figure. The dashed white line indicates the approximate location of a potential landing-site [Michalski and Fergason, 2008]. HRSC DTM height contours are displayed with an interval of $200 \mathrm{~m}$.

b) Constrained cross-section derived from the HRSC DTM and the color imagery. At least 5 color sub-units have been counted with the help of HRSC color imagery in the outcrops of the plateau. The different sub-units are indicated by $\delta 1, \delta 2, \delta 3, \delta 4$ and $\delta 5$. Those sub-units show a broad syncline at the present location of the Mawrth Vallis channel. One of the potential landing sites for the MSL mission in the Mawrth Vallis region is indicated on the northern part of the cross-section.

Figure 17: a) Inside red contours, location of detected outcrops similar to the large brown outcrop of the paleo-surface (Western most outcrop figures 8, and 10). No outcrop is larger than the one to the west, and no one shows such large filled craters. Other small outcrops could also originate from the same paleo-surface, but they are too small or are not covered by very high resolution imagery to conclude on their belonging to the same layer. The white layers indicate the locations of figures $b$ and $c$. 
b) and c): parts of HiRISE images PSP_006742_2050 and PSP_003063_2050

1232

1233

1234

1235

1236

1237

1238

1239

1240

1241

1242

1243

1244 respectively.

Figure 18: Schematic view of the deposition process. The surface of the top-most layered sub-unit could have recorded cratering before being covered by the dark material, but is eroded today when exhumed. From bottom to top: First, basal unit with impact craters recording a period of non deposition. It can correspond to the top of a lower clay-bearing unit, or to the top of the crust that was altered. Second, filling by a series of sediments in two compositional sub-units. The detected clays present in sub-units formed either during deposition or by subsequent alteration. The two color sub-units represented correspond to the minimum number of sub-units observed as in figure 8, but up to five sub-units might exist regionally. Third, a dark cap unit mantled the sediments before strong cratering. Finally, erosion removed locally the uppermost layers, exhuming the clay-bearing sub-units and the paleosurface. 
Figure 1

1246

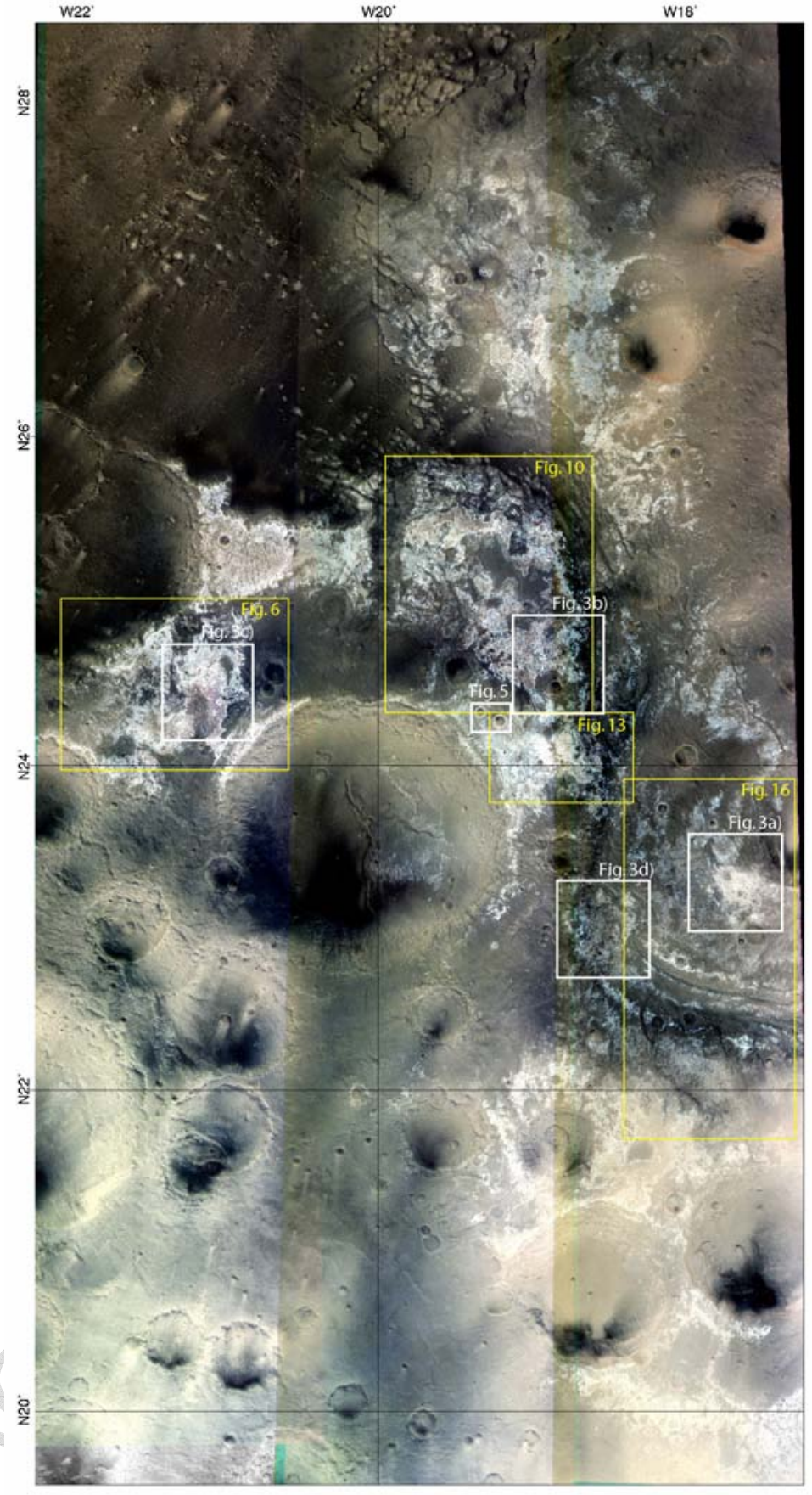


Figure 2

a) 3D object points

b) HRSC DTM
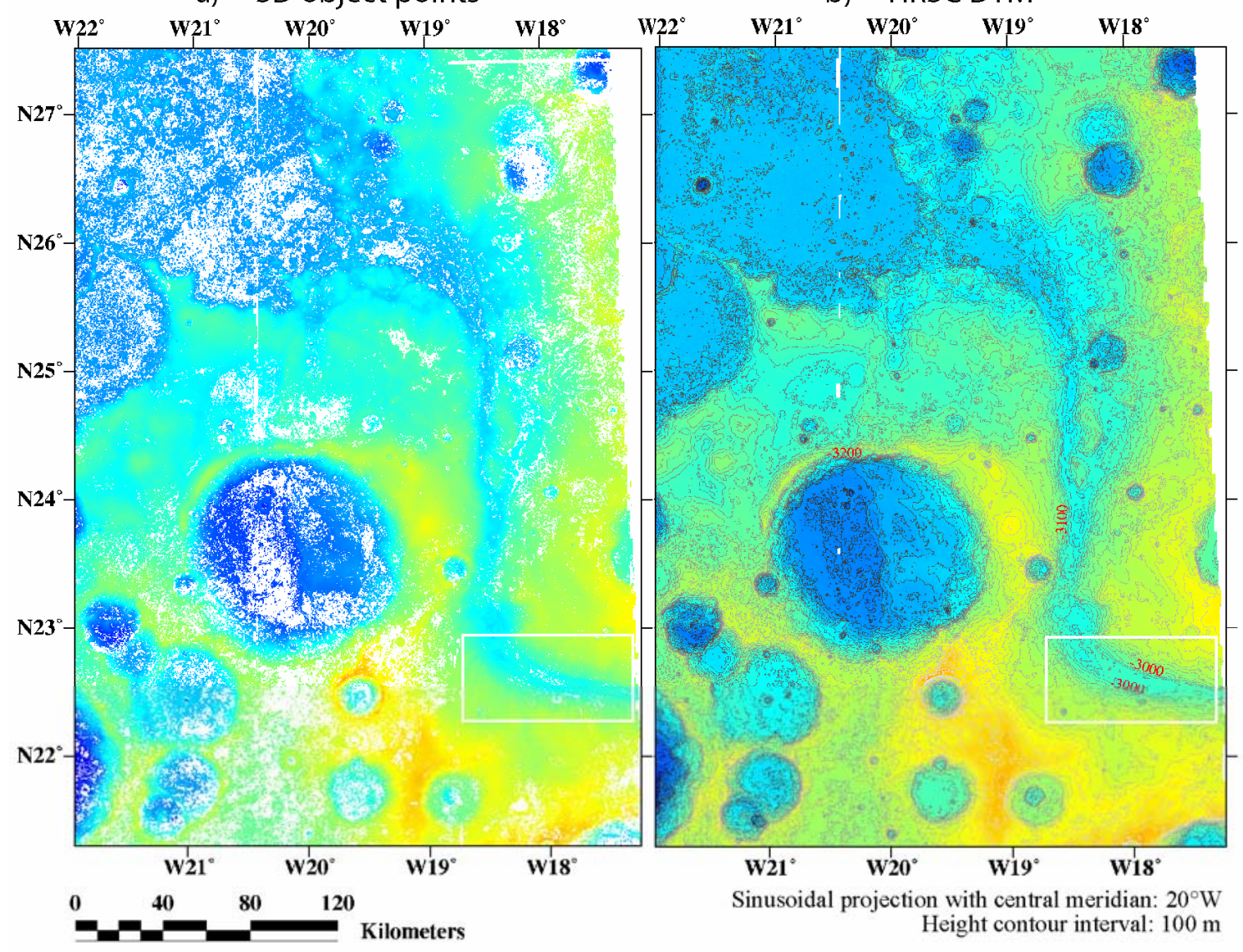

c) 3D object point close-up

d) HRSC RGB composite with HRSC DTM height contours

1249
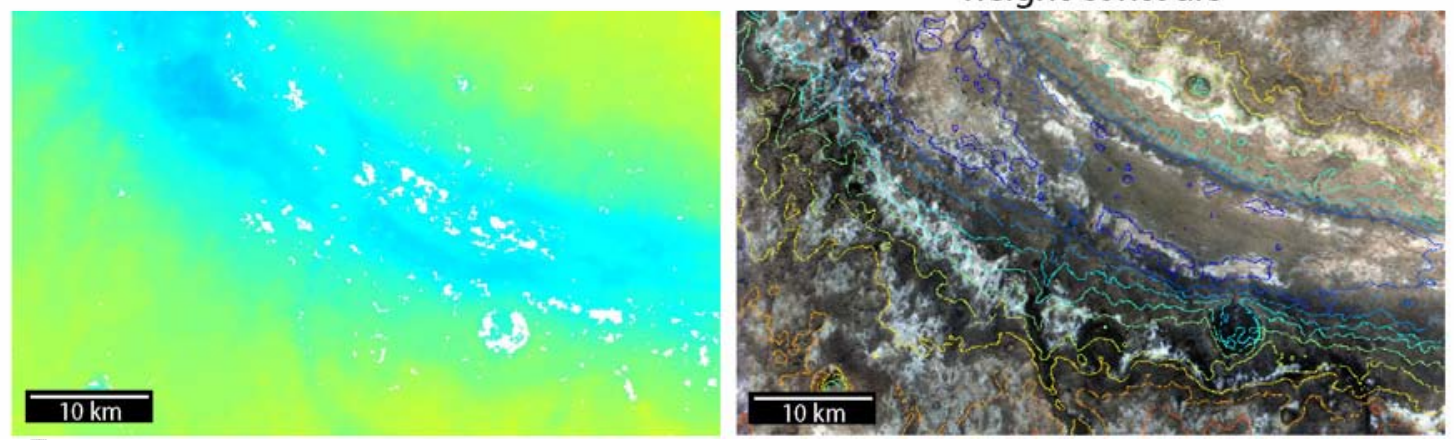
Figure 3

a)

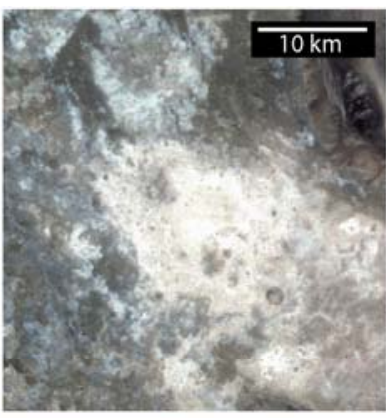

b)

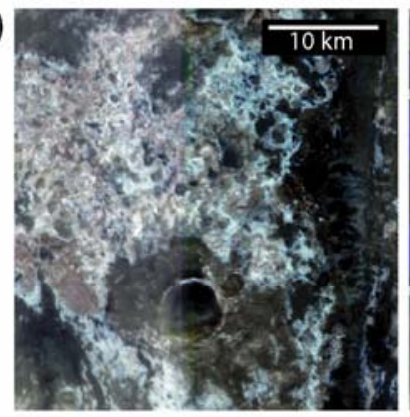

c)

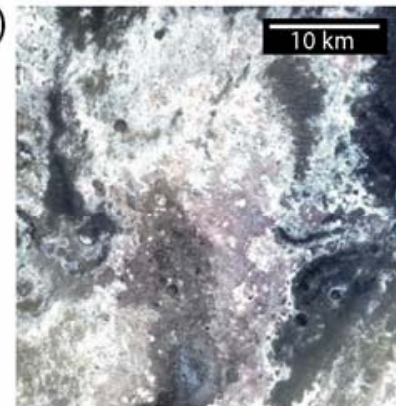

d)

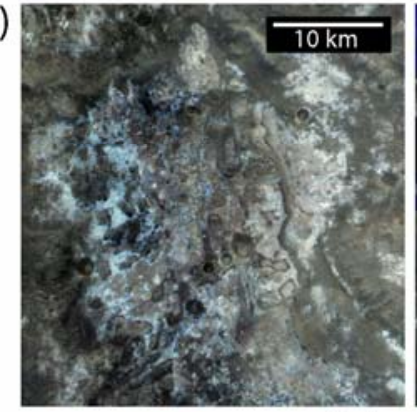

1251
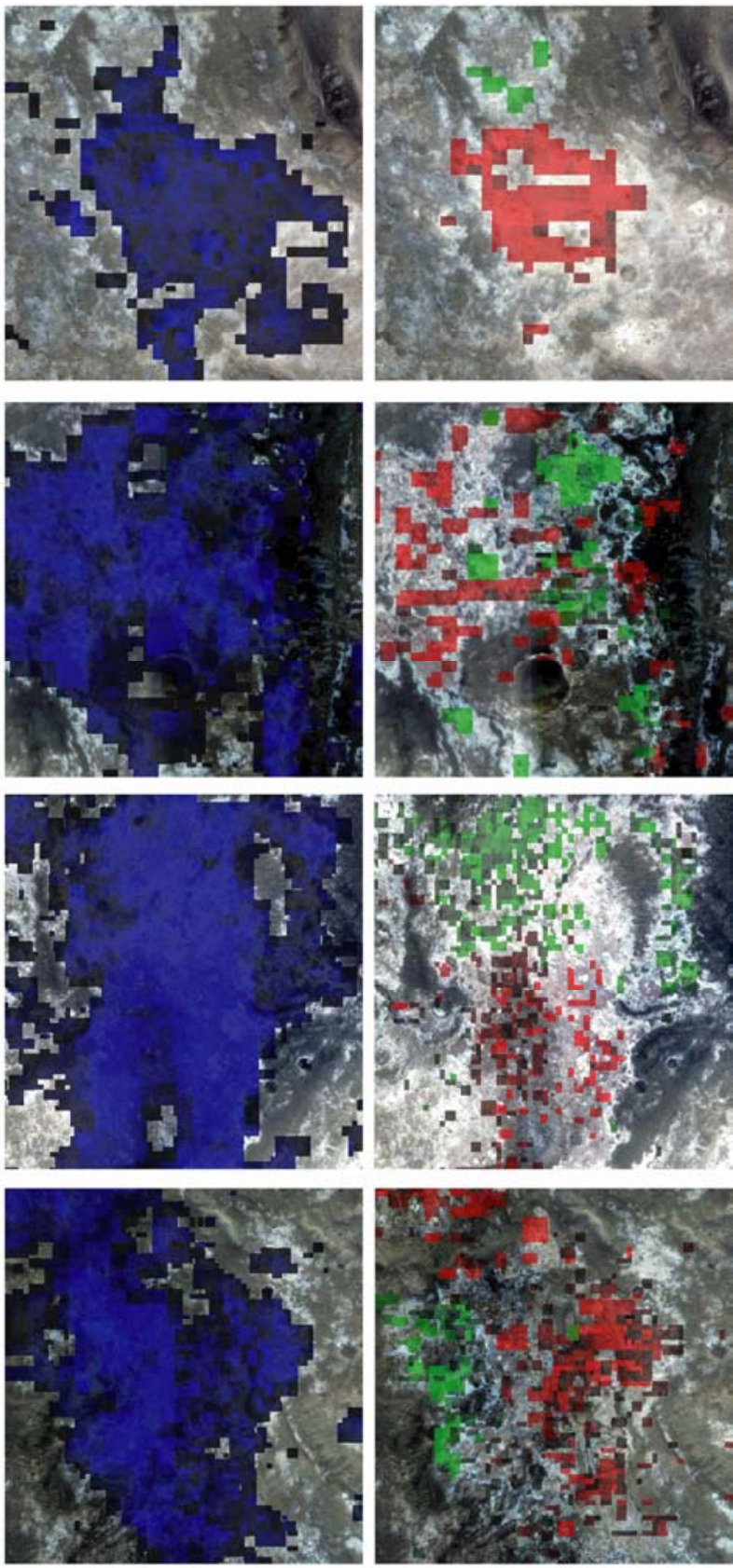

OMEGA spectral index $4 \%$ for the $2.20 \mu \mathrm{m}$ band

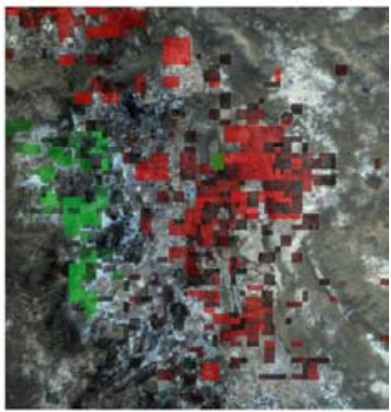

OMEGA spectral index for the $2.29 \mu \mathrm{m}$ band 
1252

Figure 4

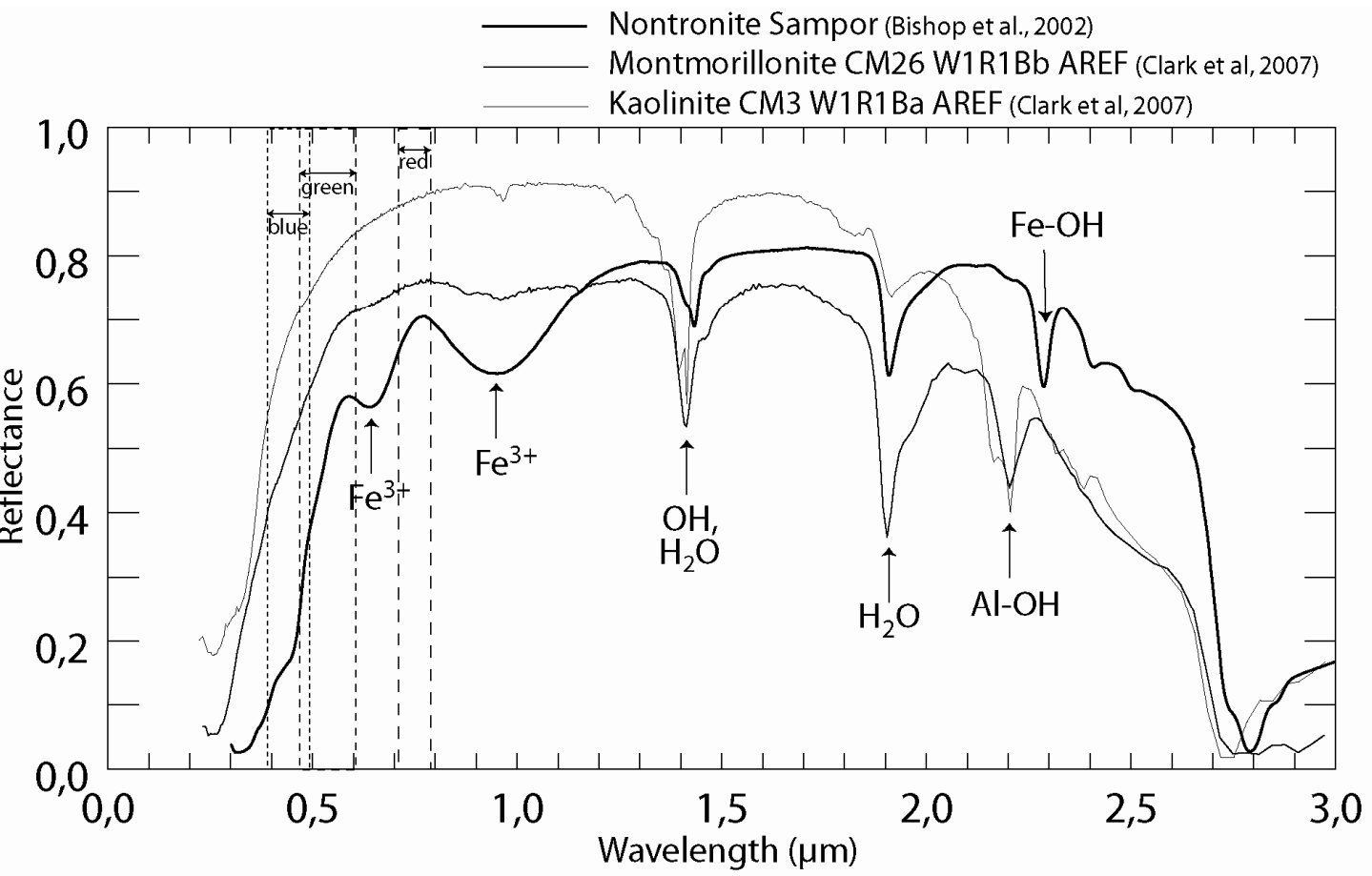

1253 
Figure 5
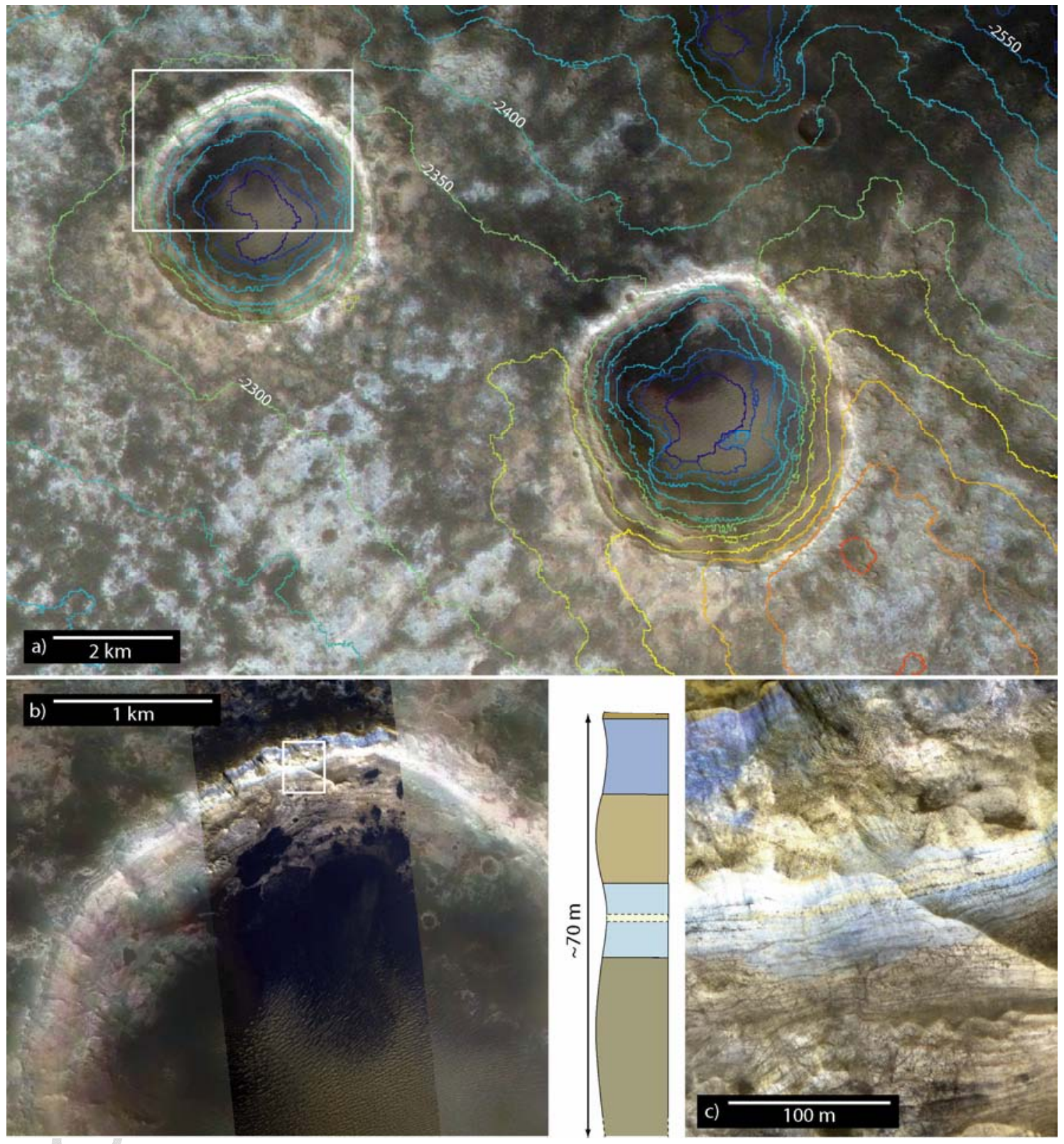

1255

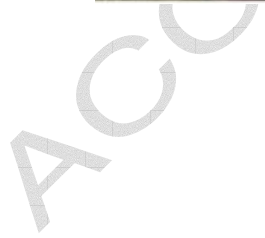


Figure 6
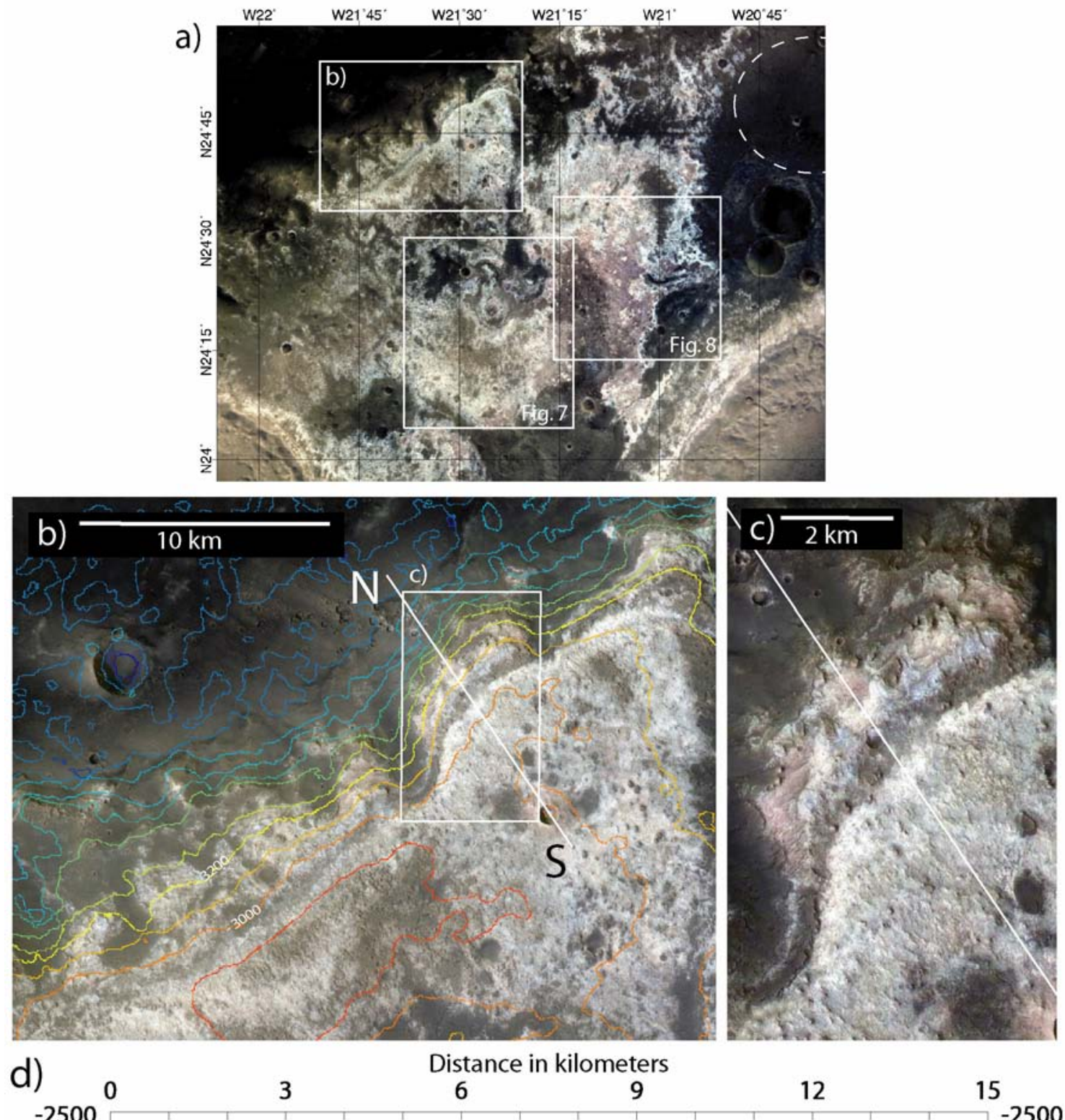

Distance in kilometers

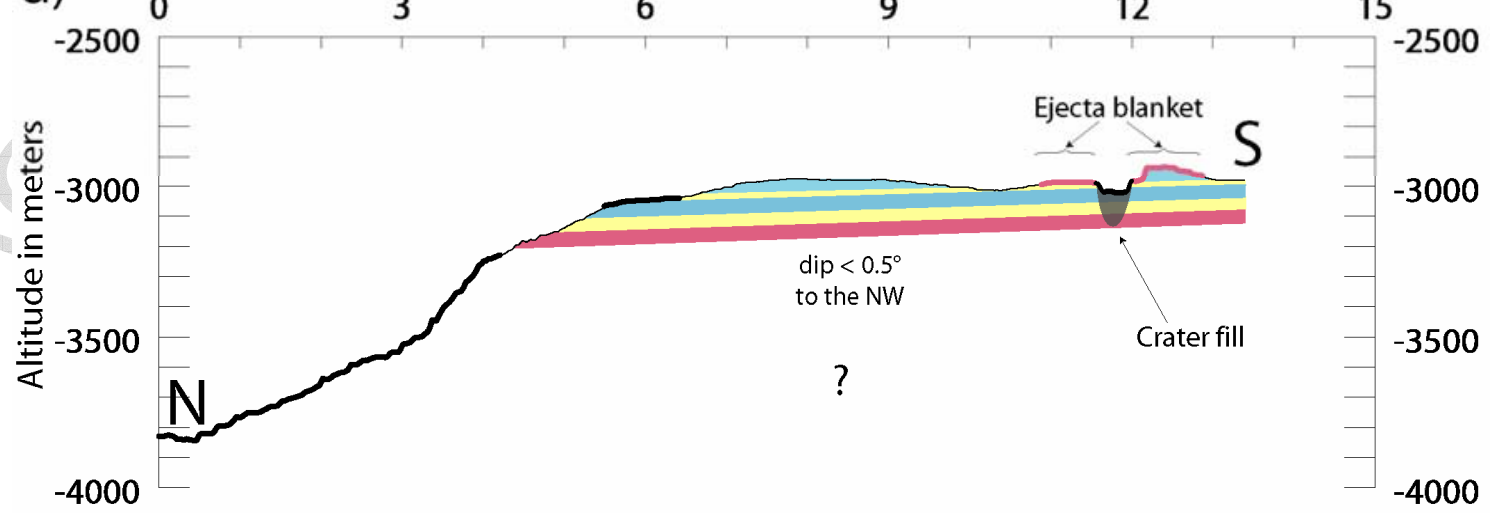


Figure 7

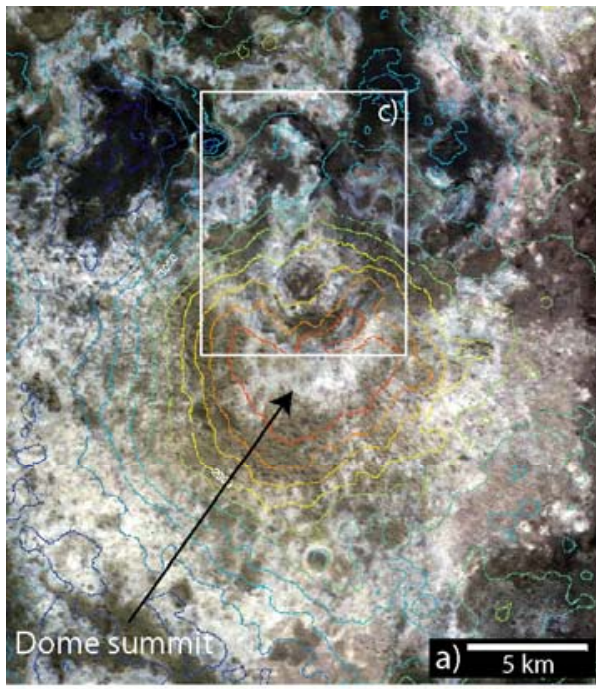

1259
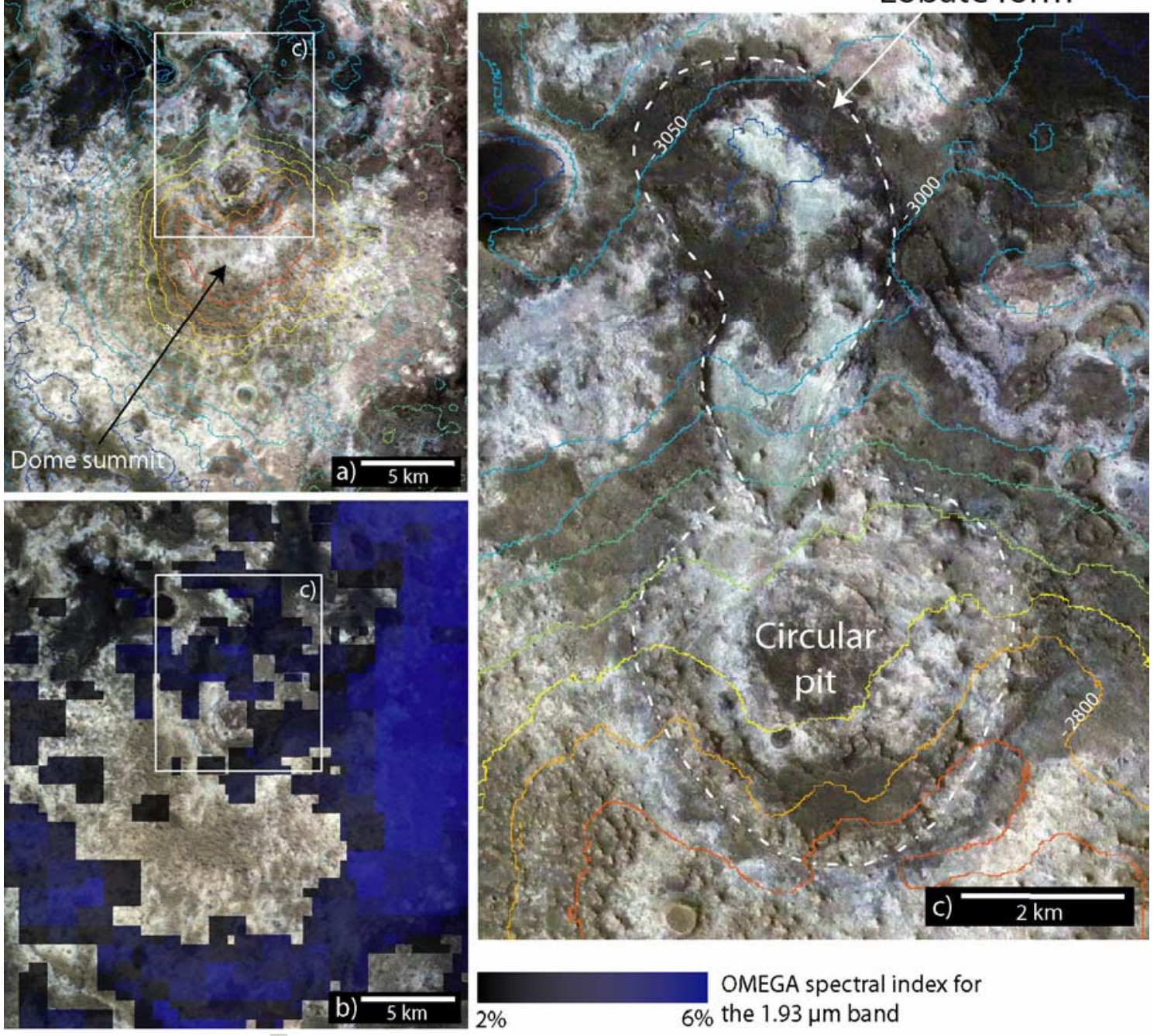

OMEGA spectral index for

$2 \% \quad 6 \%$ the $1.93 \mu \mathrm{m}$ band

\section{Lobate form}


Figure 8

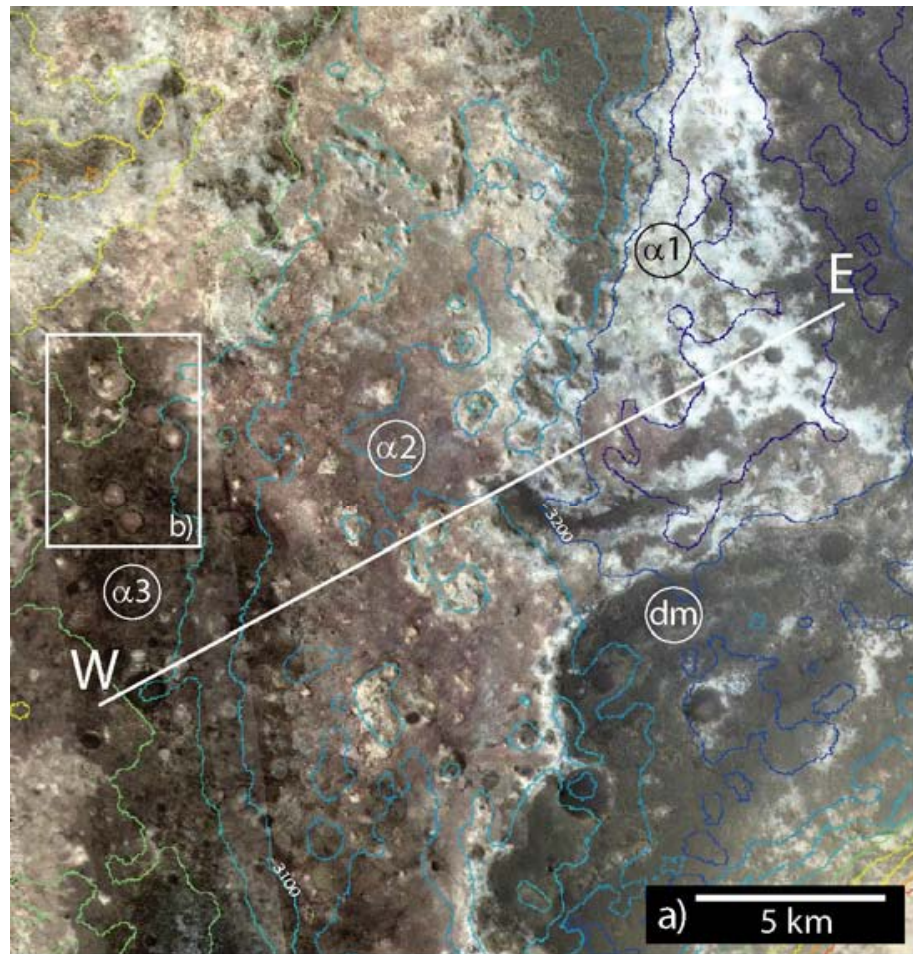

Remnant buttes of

brighter layers $\downarrow$ Paleo-surface
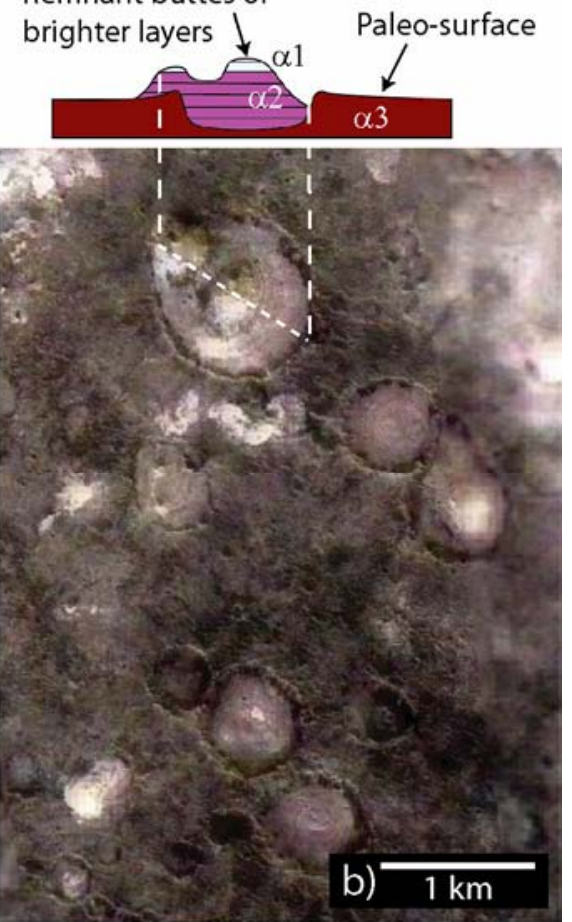

c)

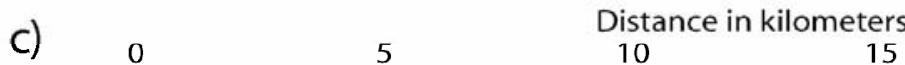

Distan
10

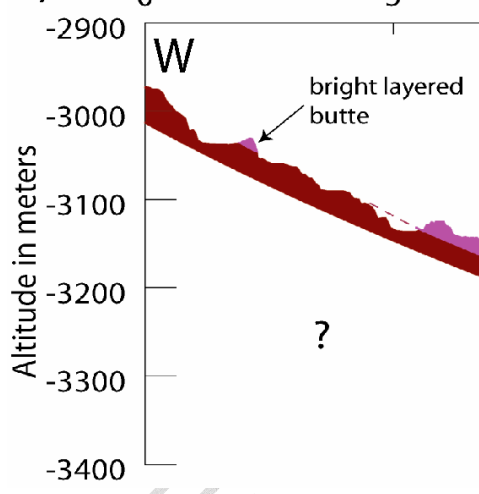

25

$-2900$

$-3000$

$-3100$
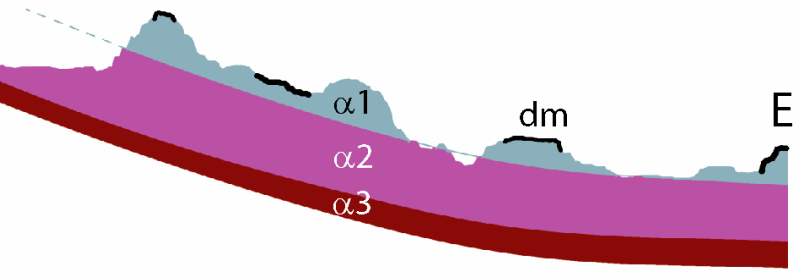

$-3200$

$-3300$

1261

$-3400$ 
1262

\section{Figure 9}

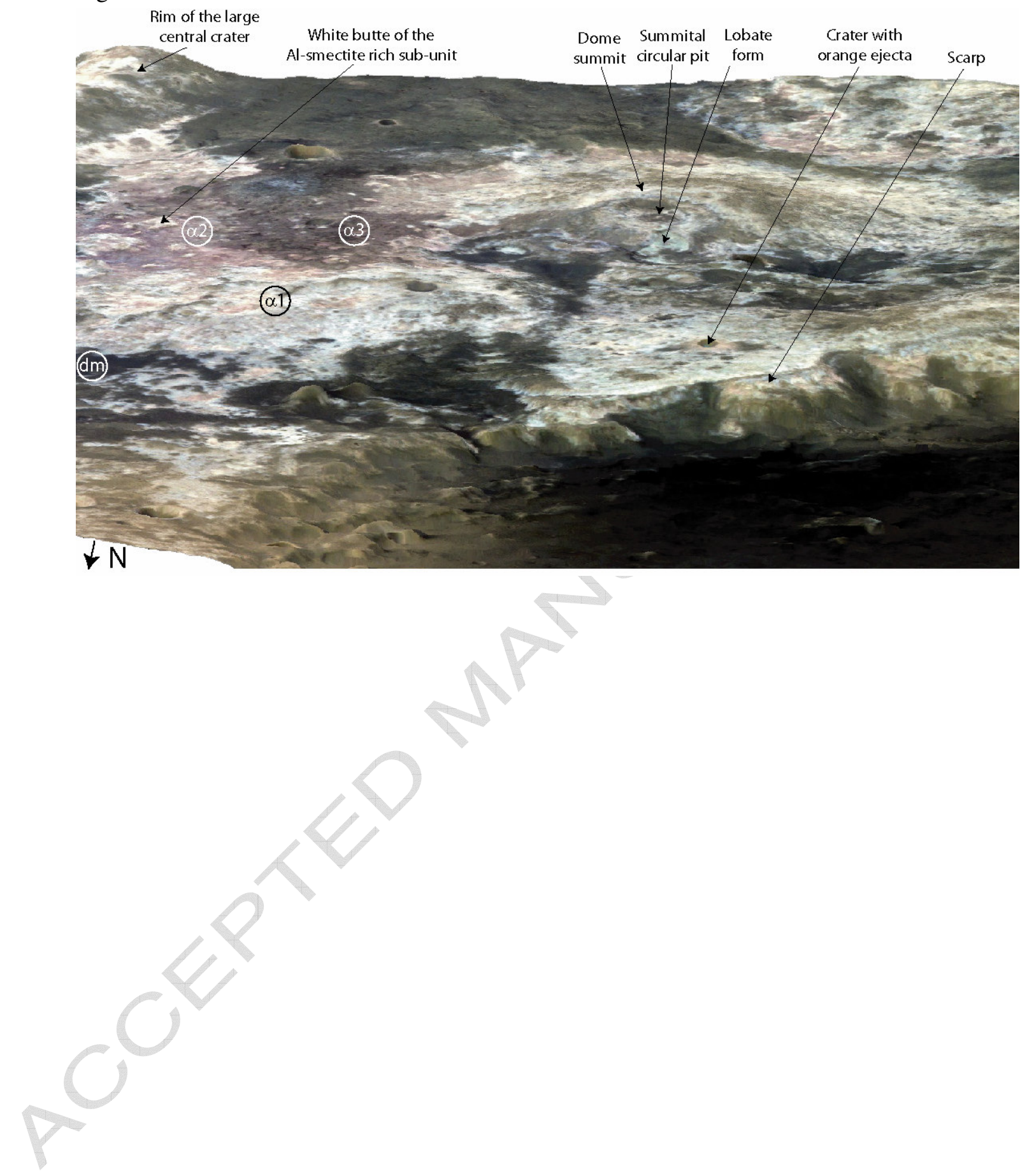


Figure 10
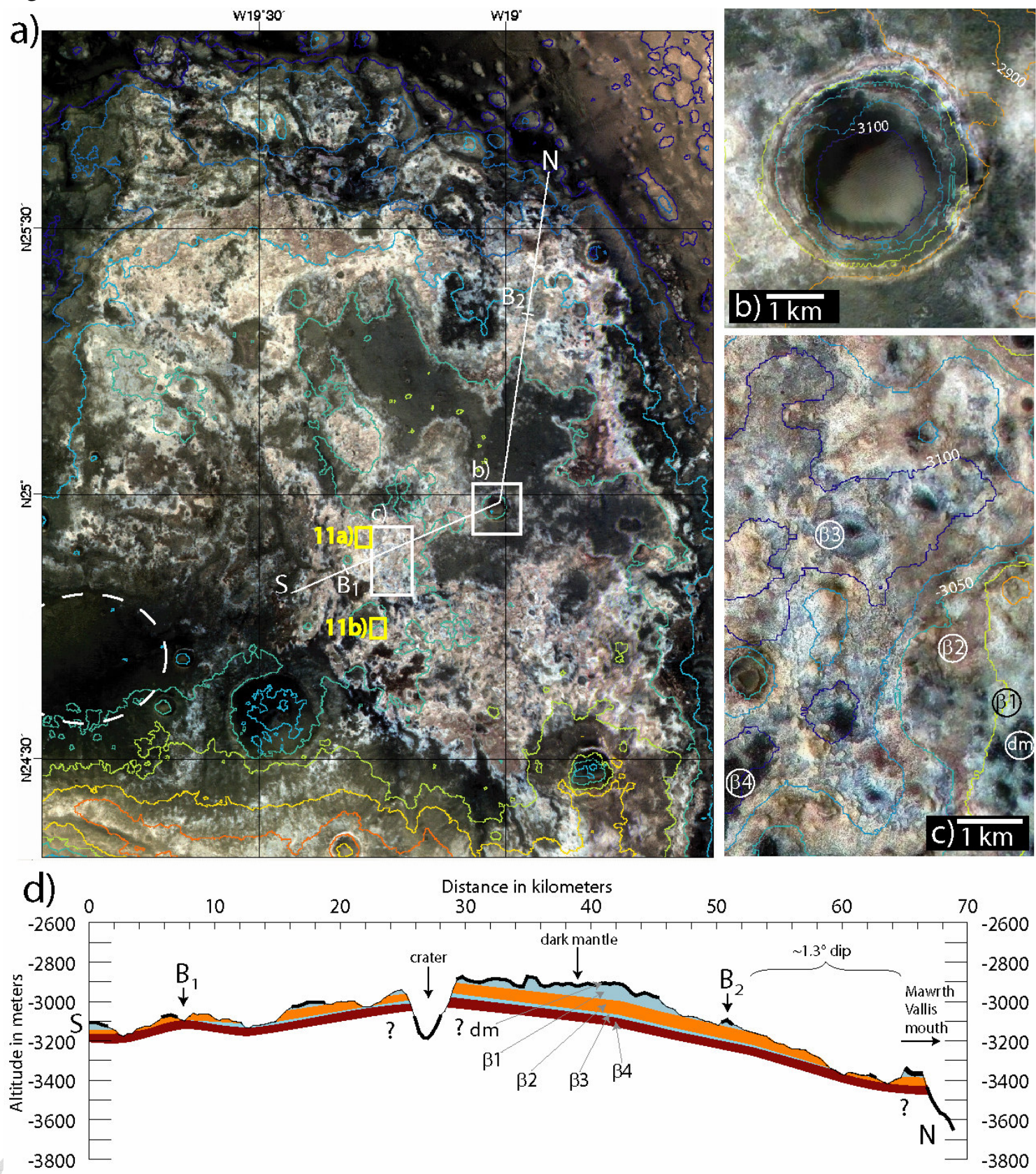

1265 
Figure 11
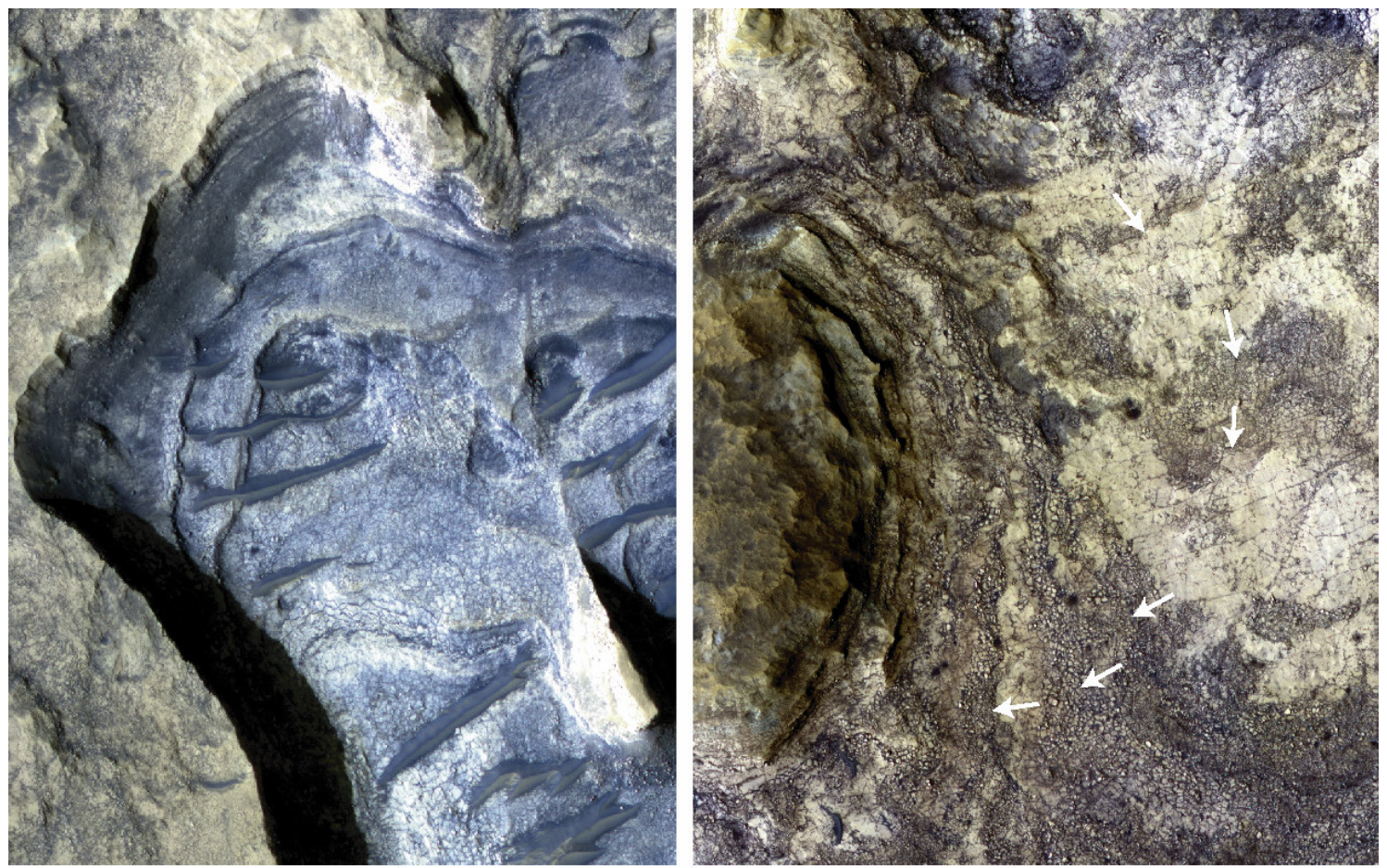

1267

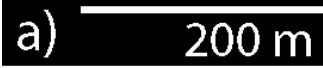

b) $200 \mathrm{~m}$

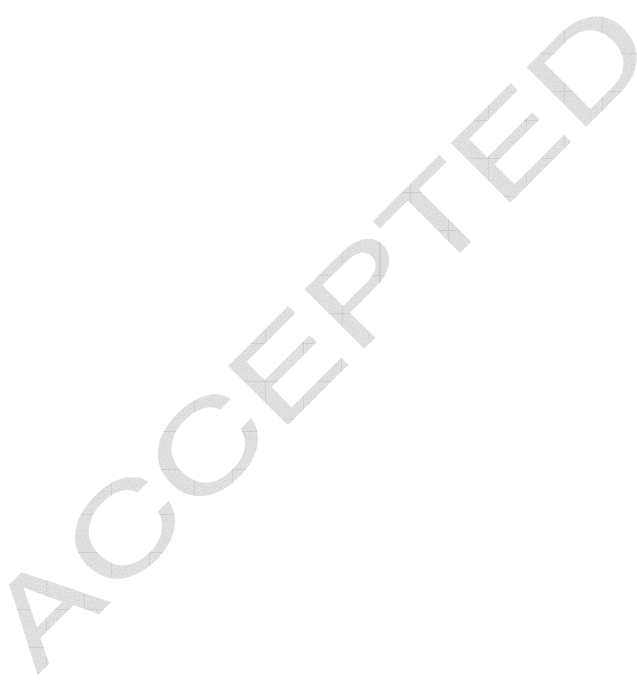


Figure 12
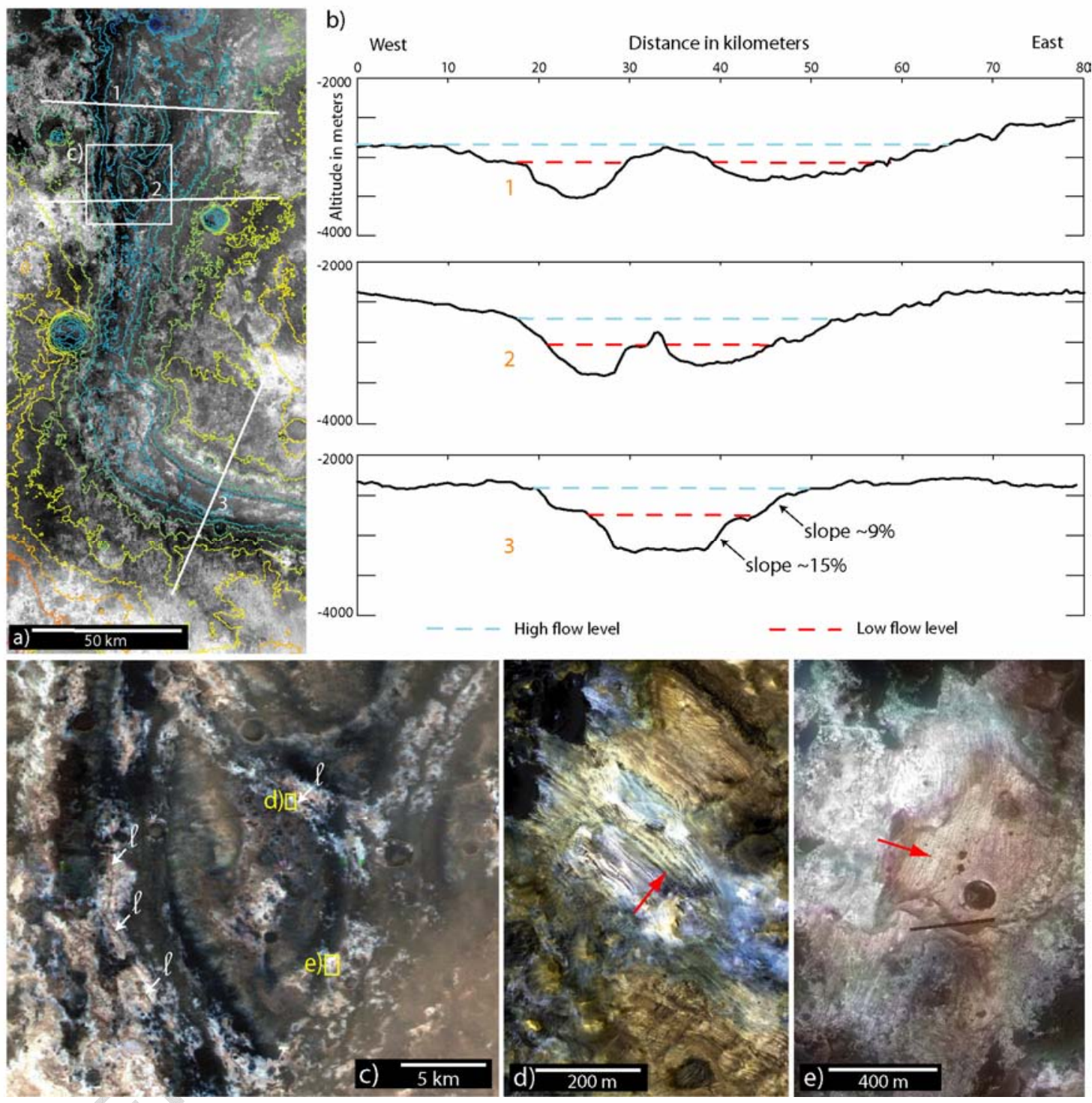
1270

Figure 13

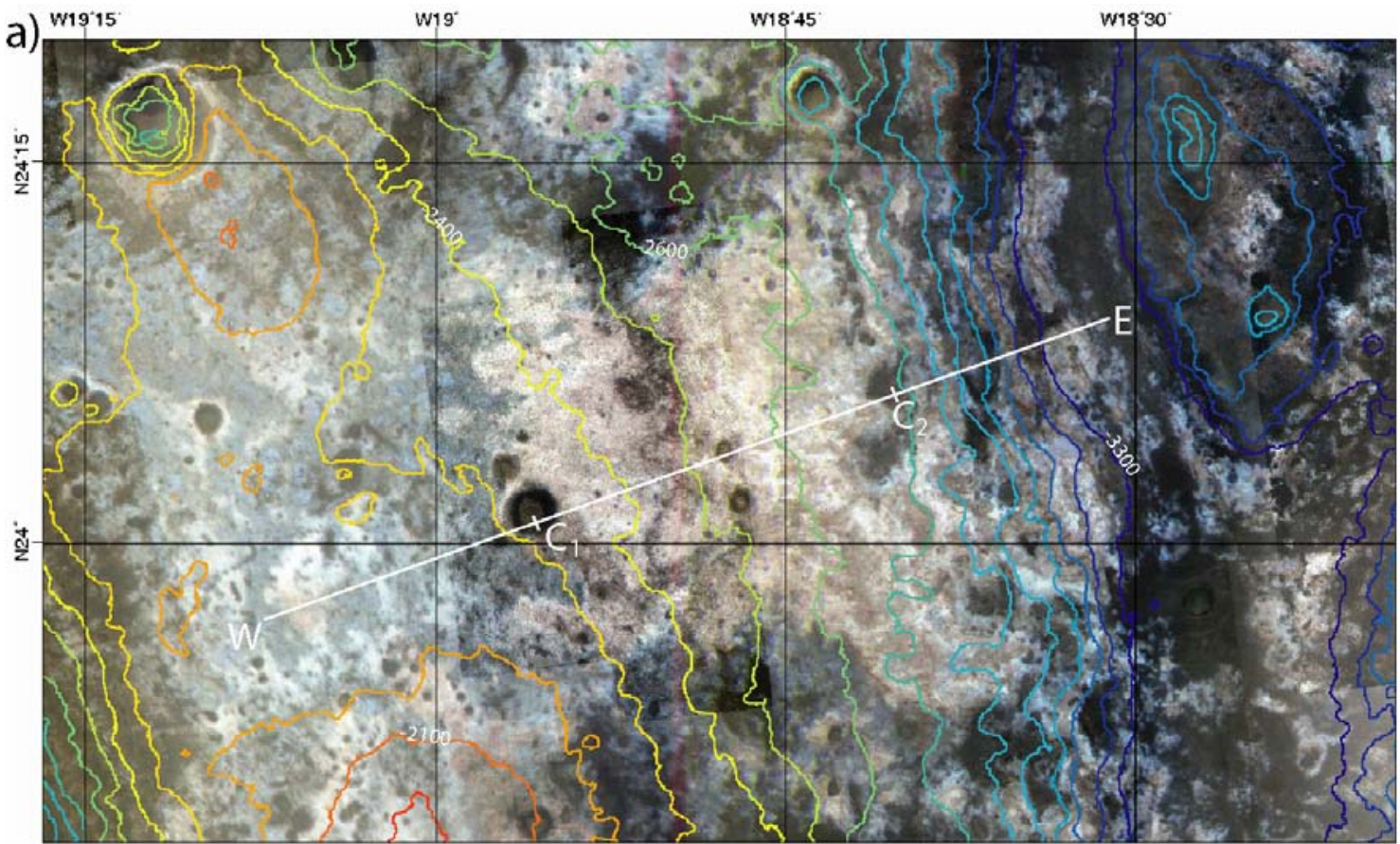

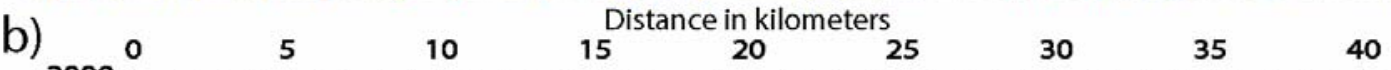

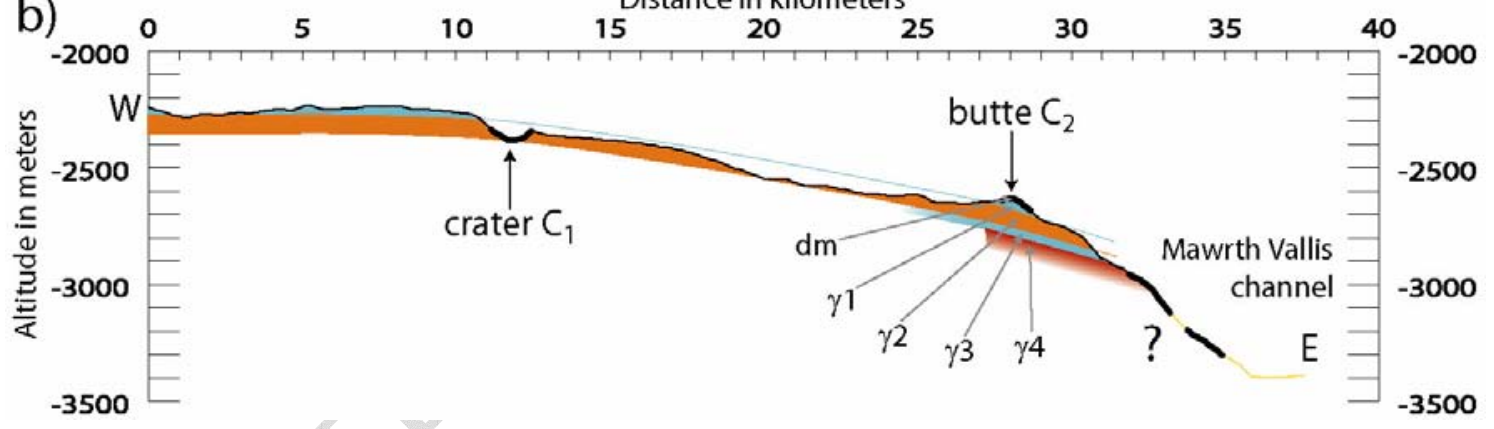

1271 
1272

Figure 14

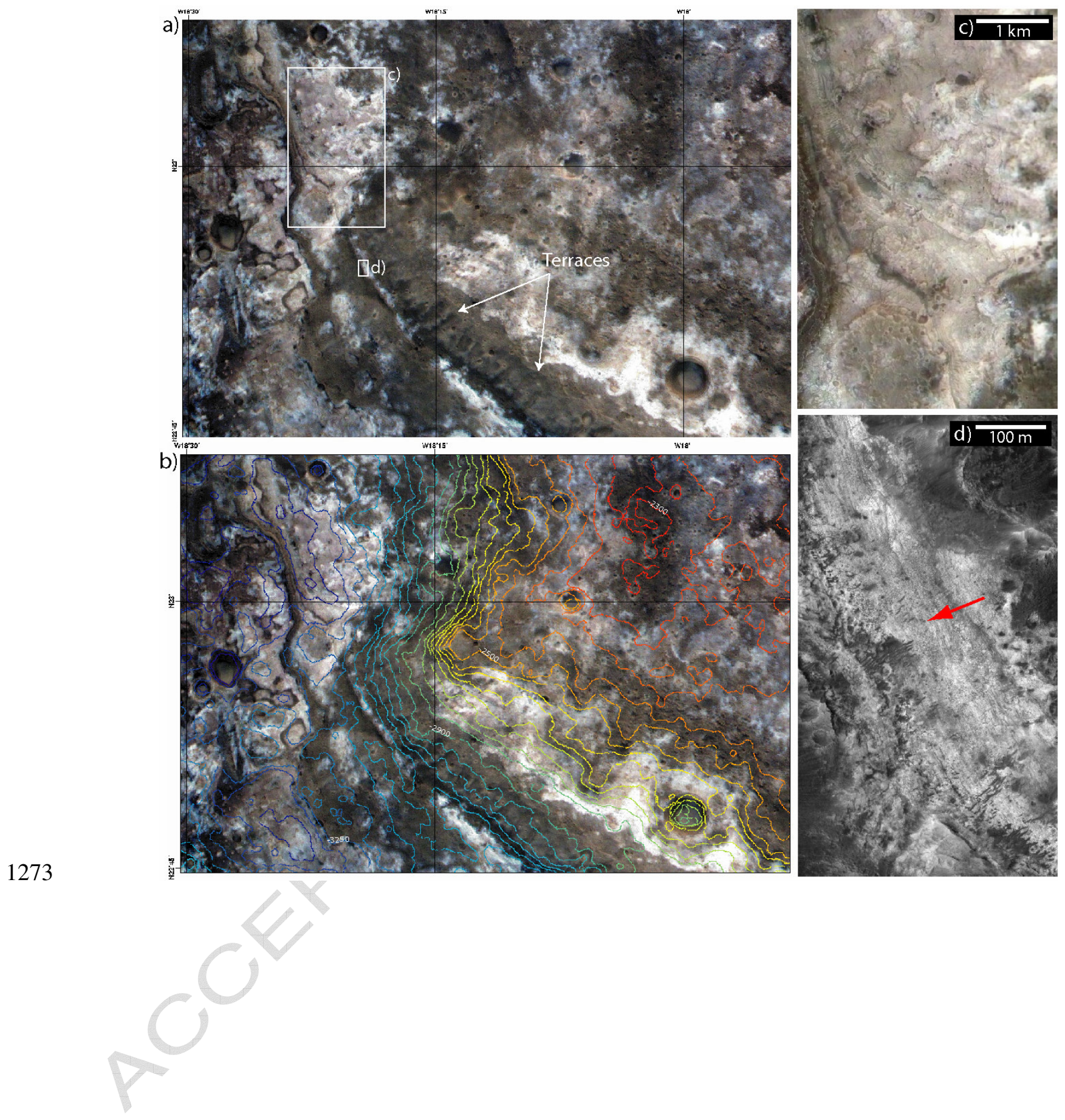


1274

Figure 15

a)
-2500

Distance in kilometers
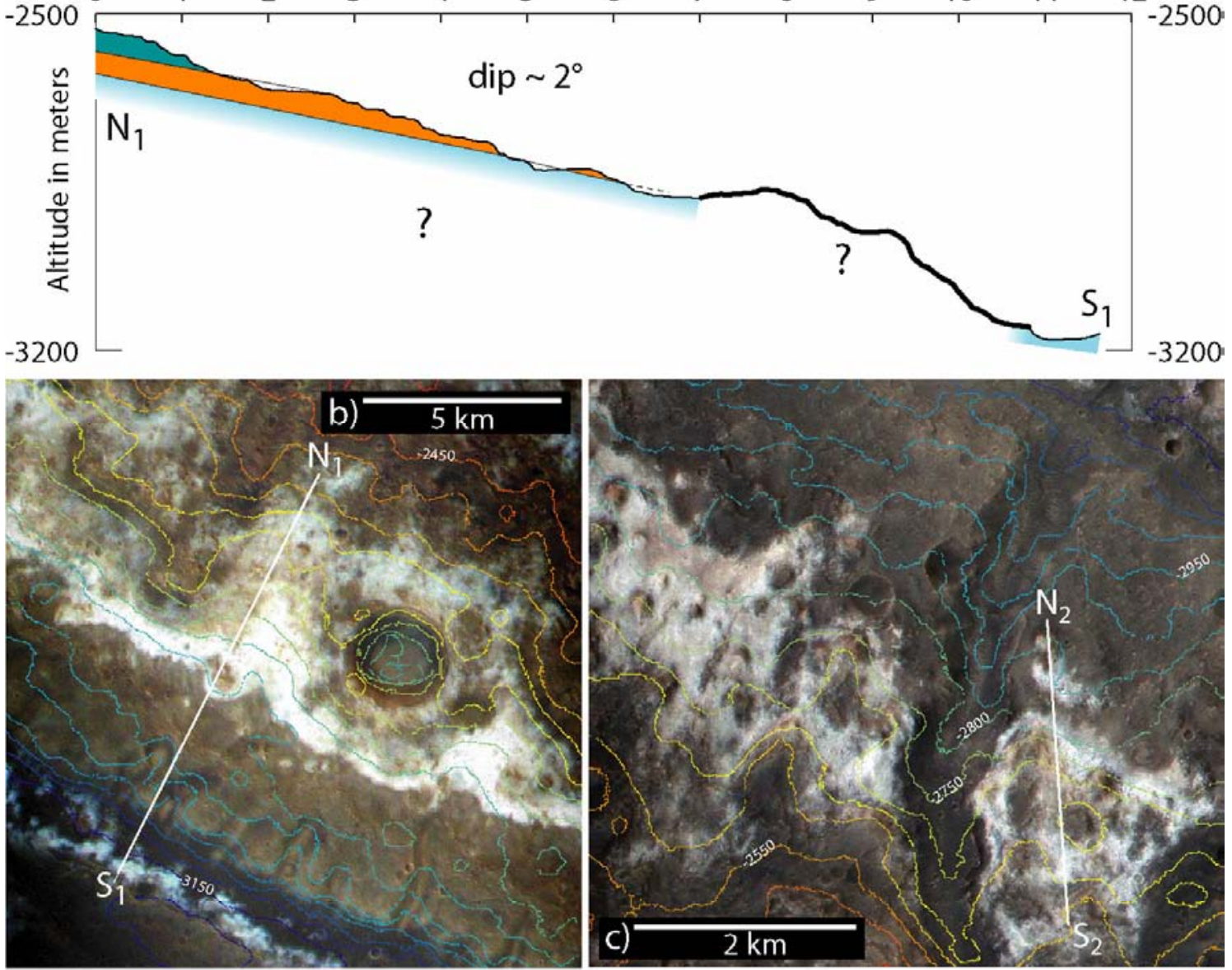

d)

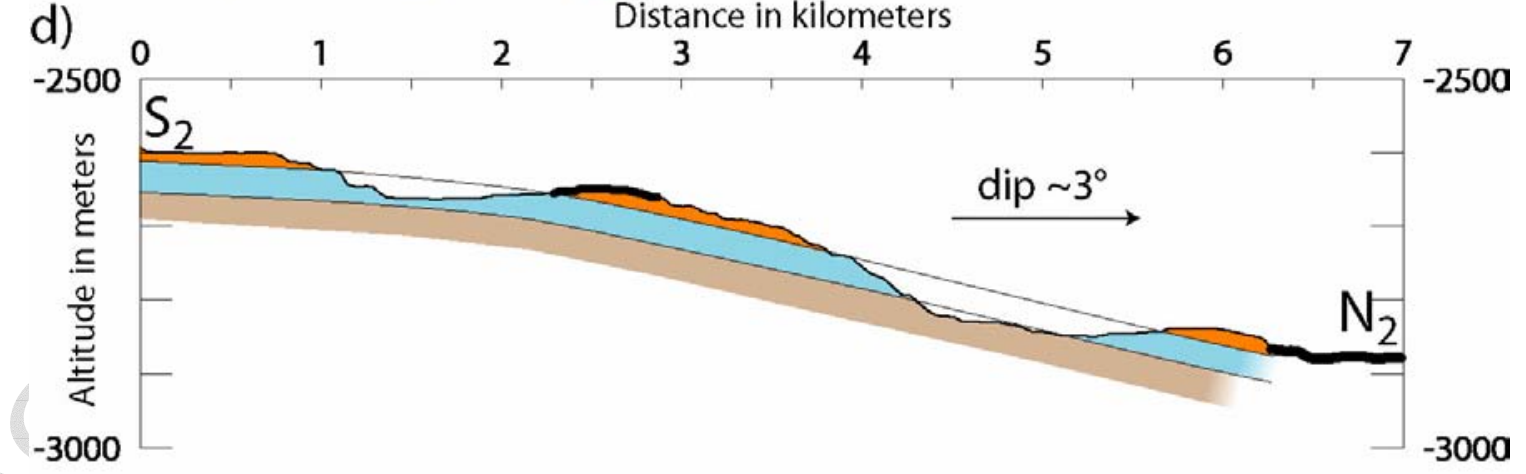

istance in kilometers

1275 
Figure 16

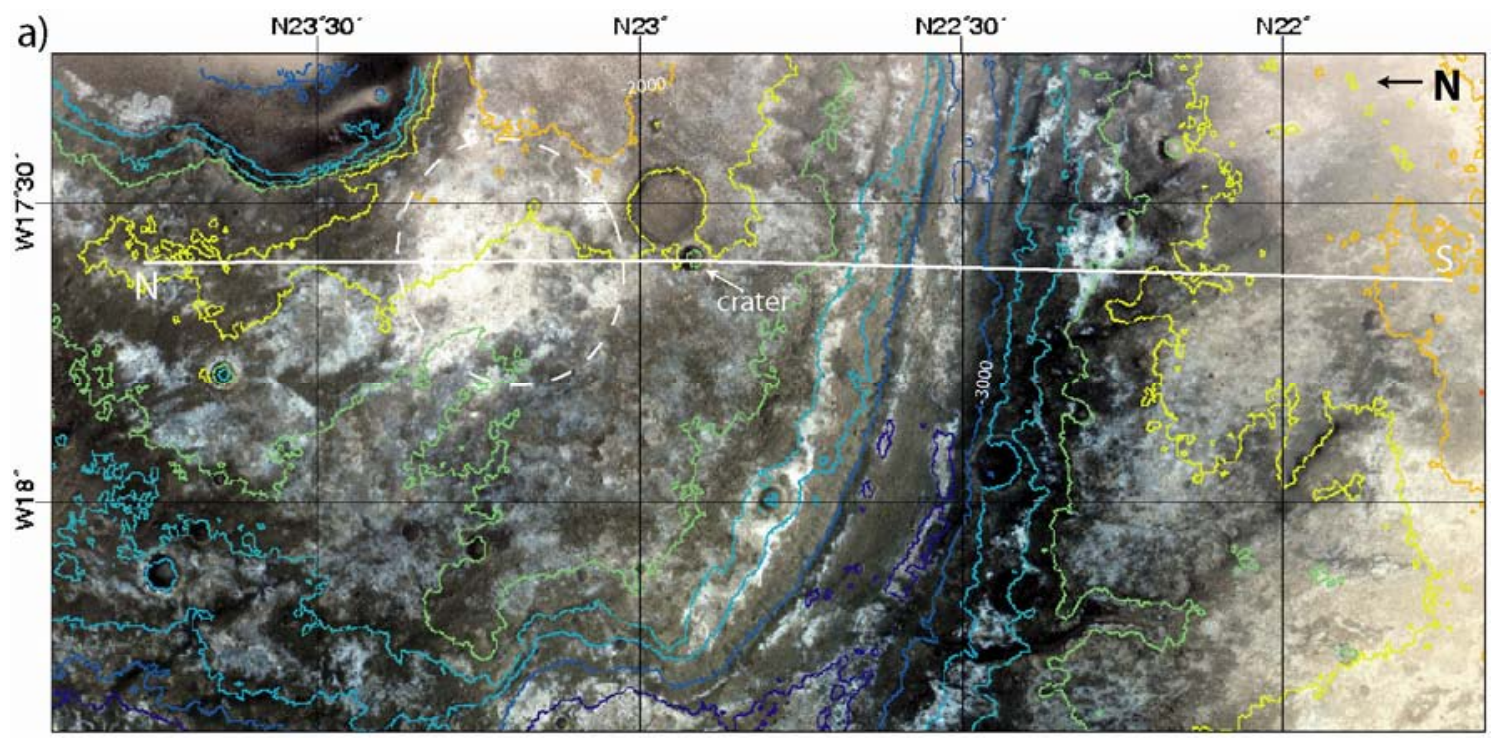

b)

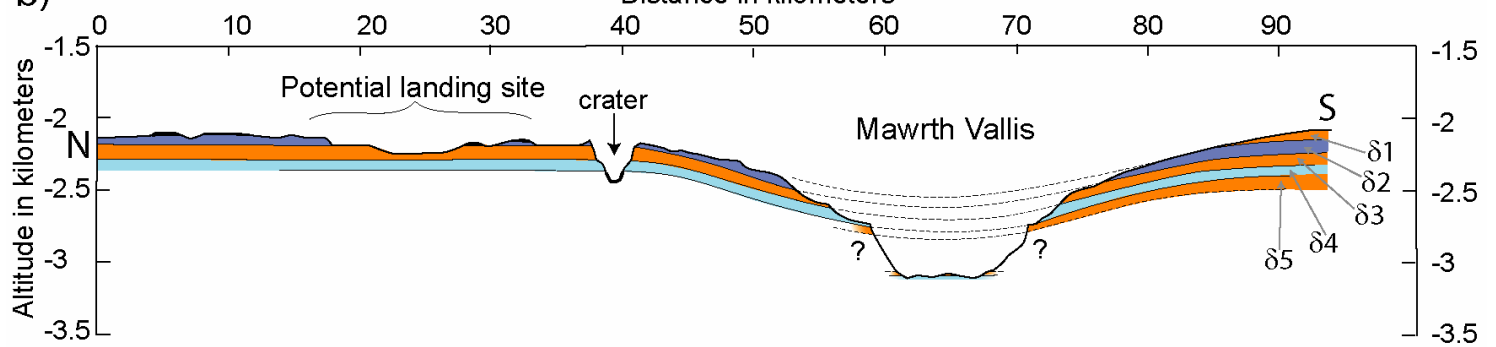

1277 
Figure 17

a) $121 " 30$

W21

W $20^{\circ} 30^{\prime}$

W20"

W19"30

W19"
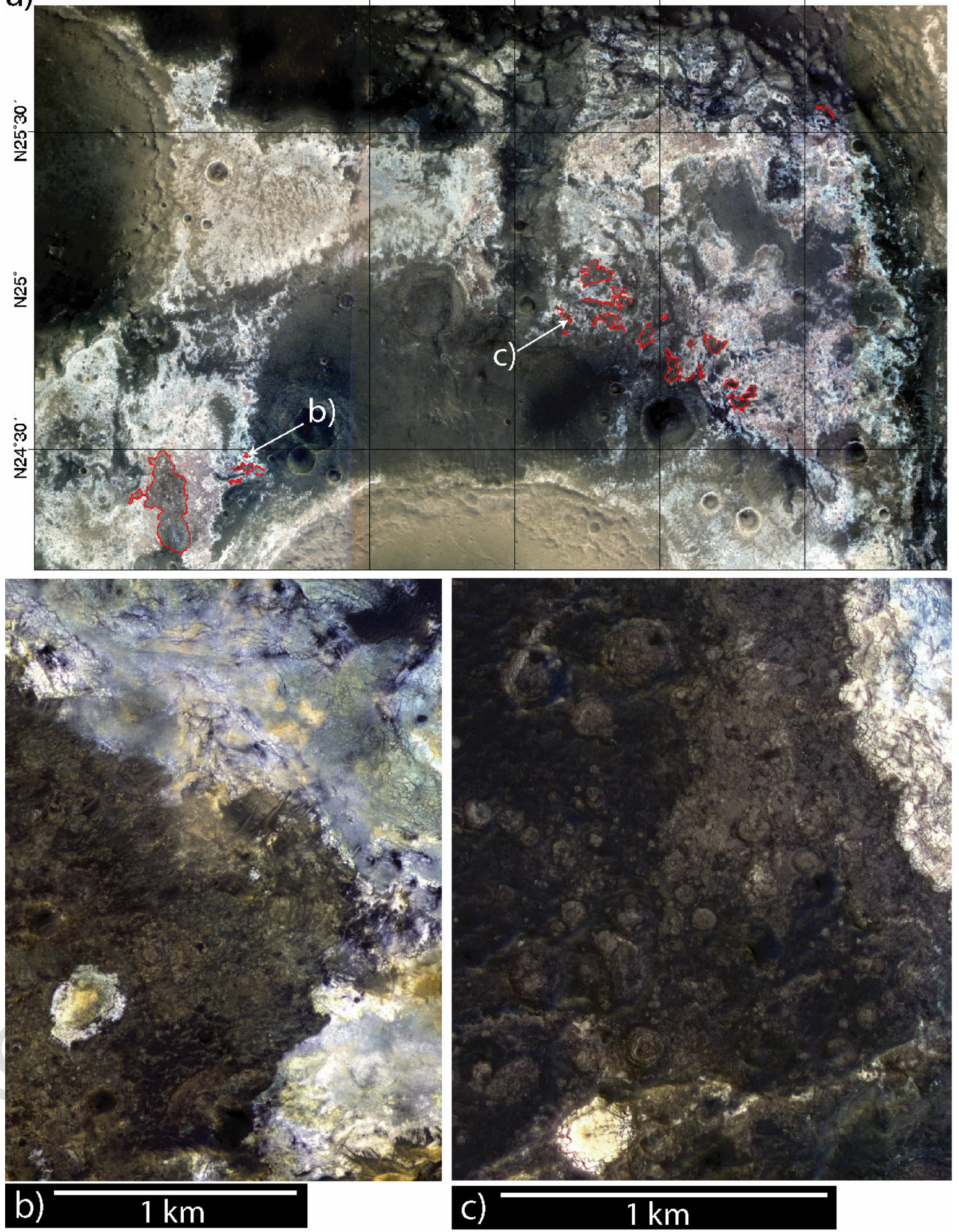

1279

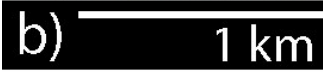

c)

$\mathrm{km}$ 
Figure 18

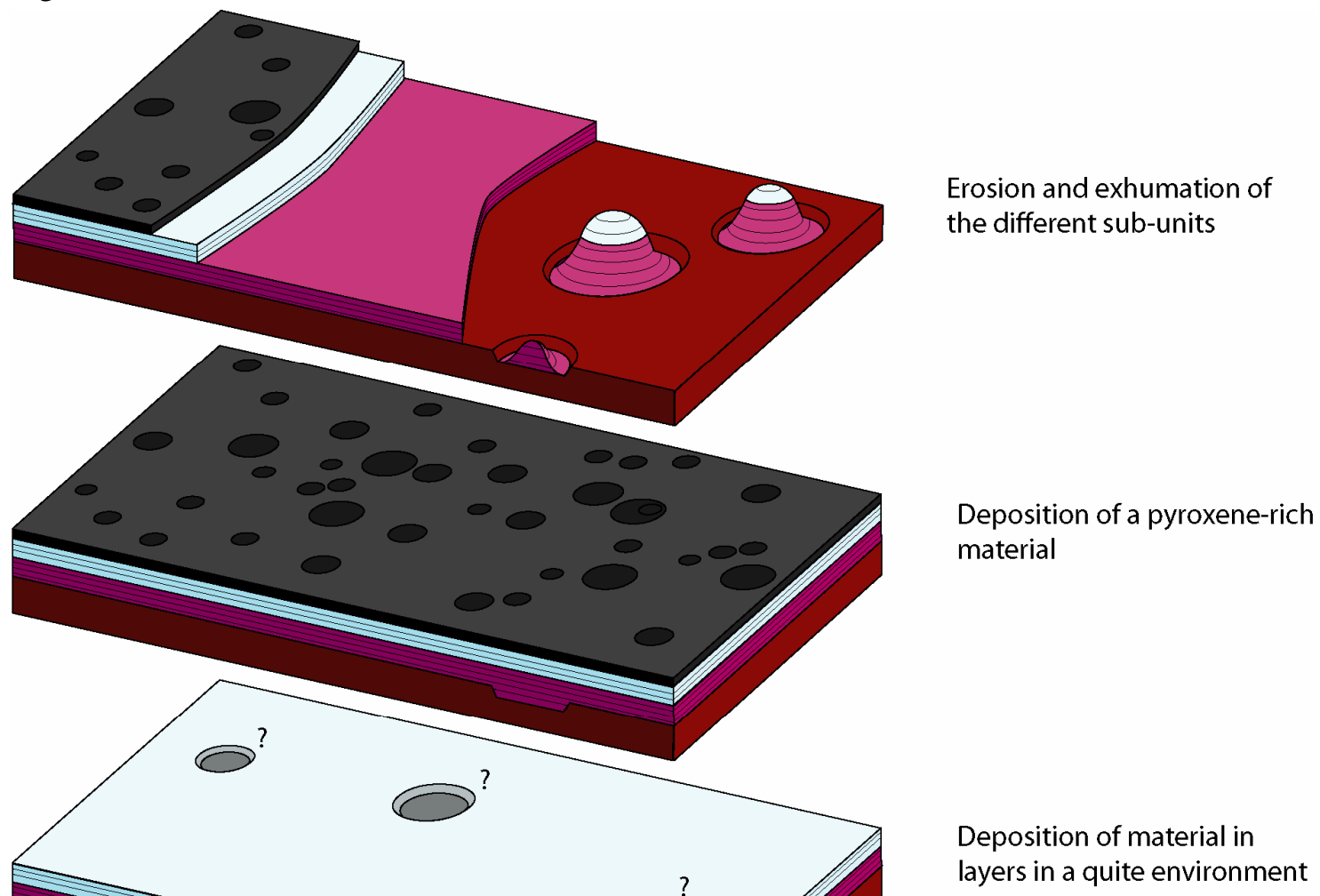

1281

1282

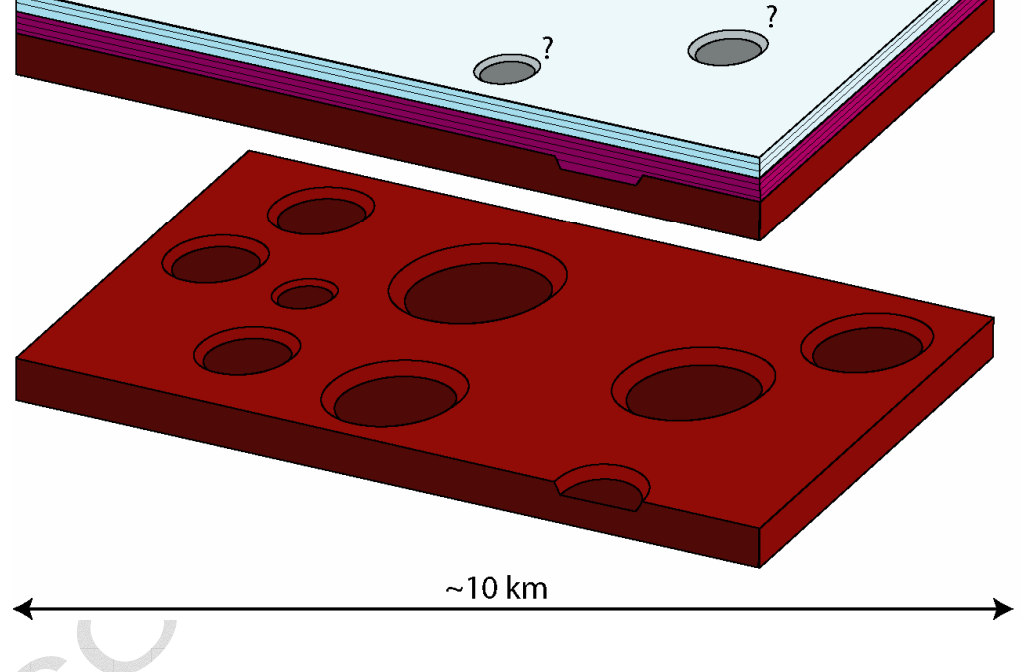

